\title{
Investigating the Propagation of the Colloidal Dispersion Gel (CDG) in Thick Heterogeneous Reservoirs Using Numerical Simulation
}

\author{
Tariq Khamees*, Ralph Flori
}

Department of Geosciences, Geological, and Petroleum Engineering, Missouri University of Science and Technology, Rolla, United States

Email address:

tkkgy9@mst.edu (T. Khamees)

${ }^{*}$ Corresponding author

\section{To cite this article:}

Tariq Khamees, Ralph Flori. Investigating the Propagation of the Colloidal Dispersion Gel (CDG) in Thick Heterogeneous Reservoirs Using Numerical Simulation. American Journal of Science, Engineering and Technology. Vol. 4, No. 1, 2019, pp. 1-17. doi: $10.11648 /$ j.ajset.20190401.11

Received: January 17, 2019; Accepted: February 25, 2019; Published: March 16, 2019

\begin{abstract}
Over the last few decades, there has been a dispute regarding the ability of colloidal dispersion gels (CDG) to improve sweep efficiency more than polymer flooding. In this study, a numerical model was built using the CMG-STARS simulator to investigate the behavior of injecting $0.1 \mathrm{PV}$ of CDG slug into one quarter of inverted nine-spot pattern. This slug was composed of 0.1 wt. \% HPAM polymer solution with a polymer-to-crosslinker ratio $(\mathrm{P} / \mathrm{X})$ of 50/1. The model was represented by a thick heterogeneous reservoir with high water cut caused by high heterogeneity and adverse mobility ratio. Different experimental results from published literatures have been implemented in the numerical model to study the effect of these parameters on the propagation of the CDG. The results confirmed that CDG could propagate deep into the thief zones and reduce their permeability more than polymer solution. Moreover, the results showed that the shear-thinning behavior of CDG could assist the selective penetration into the high-permeability streaks only, thus reducing the cost of isolating the thief zones by mechanical methods. In addition, the results showed that the wettability had tremendous effects on the treatment. Therefore, the water-wet system yielded higher results with less damage to the low-permeability layers compared to the oil-wet system. The results showed an overestimation of the performance of post-treatment water when considering irreversible adsorption of CDG. However, the prolonged injection of post-treatment water would not remove the permeability reduction caused by CDG flooding, even with reversible adsorption. The results revealed that the higher the degradation of the CDG, the lower the recovery factor. The results showed the importance of considering a combination injection of polymer and CDG. The results also revealed that the higher the salinity of the reservoir brine and/or the makeup water, the lower the recovery factor. In addition, as the polymer/crosslinker ratio increases, the recovery factor decreases, while as the polymer hydrolysis increases, the recovery factor and residual resistance factor increases.
\end{abstract}

Keywords: Colloidal Dispersion Gel, Heterogeneous Reservoirs, Numerical Simulation, In-Depth Treatment

\section{Introduction}

Prolonging the life of mature reservoirs and reducing excess water production are big challenges in the oil industry because high water cut causes serious economic and environmental impacts. Different conformance treatment methods have been utilized to mitigate this problem, such as the injection of dispersion microgels to reduce water production and to improve sweep efficiency.

Colloidal dispersion gel (also known as weak gel, microgel dispersion, weak viscoelastic fluid, crosslinked polymer, deep diverting gel, or low concentration flowing gel) [1], is applied only to injection wells. The colloidal dispersion gel is composed of mixing low concentrations of high molecular weight of partially hydrolyzed polyacrylamide (HPAM) and inorganic crosslinkers, such as chromium or aluminum; thus, there is no enough polymer to form a bulk gel or continuous network [1-5]. The molecular weight of the HPAM is from 8 to 17 million Daltons, and the polymer/crosslinker (P/X) ratio is from $30 / 1$ to $60 / 1$ [1]. However, this ratio could be in 
the range from 20/1 to 100/1 [6]. CDG could be considered a mid-point between easy to flow uncrosslinked polymer and not easy to flow bulk gel $[1,2,7]$.

The successful field applications of CDG introduce it as a substitute to uncrosslinked polymer solution, with the ability to achieve high level of permeability reduction in the highpermeability layers. Until 2011, more than 70 CDG floods were implemented in the United States and worldwide, such as the Rocky Mountain Region (USA), Loma Alta Sur and the El Tordillo fields (Argentina), the Dina Cretaceous field (Colombia), and the Daqing, the Shengli, and the Karamay oil fields (China) [6-12]. These field applications proved the ability of large volumes of CDG to propagate deep into the reservoir without injectivity problems and can generate higher viscosity and increase the resistance factor substantially compared to uncrosslinked polymer [6, 7, 9, 1317]. However, there is a debate about the mechanism, propagation, and economics of $\mathrm{CDG}$ as an in-depth gel treatment [3, 18-20]. The main question is about the propagation of the CDG aggregate deep into the highpermeability layers, which could cause a permeability reduction in these layers more than polymer solution. Those authors claim that once the gel particles have grown to the size of the pore throats, the gel will not be able to propagate deep through porous rock.

Different factors should be taken into account when selecting CDG in field applications, such as shear rate and salinity. Shear rate affects the formation of $\mathrm{CDG}$, which makes the CDG demonstrate shear-thinning behavior $[6,18$, 21]. This shear-thinning behavior is important from the injectivity standpoint, which is very favorable in field applications of chemical-enhanced oil recovery [1]. Moreover, the gelant solution can flow as uncrosslinked polymer near the wellbore and enter selectively into the highpermeability layers [6]. On the other hand, CDG strength decreases when the salinity increases because of the buckle of polymer coils boosted by the presence of salt [6, 22]. Diaz et al. (2008) stated that, at low polymer concentrations fresh water was not necessary to form CDG that was used in the Loma Alta Sur field in the Neuquén Basin of Argentina. However, oil fields with high salinity were considered unsuitable for the application of CDG.

In this study, a 3D model, including one injector and three producers, was built using CMG-STARS simulator. The main objective of this study was to examine the role of different parameters on the propagation of CDG and to compare the obtained results with polymer flooding to ensure that CDG could increase the resistance factor more than polymer flooding.

\section{CMG-STARS Simulator}

\subsection{Gel Modeling}

The gel modeling in STARS is mainly based on the interaction of chemicals and adsorption/retention of a blocking agent. To form gel, a chemical reaction needs to be defined. When gelant is injected, it should contain an adsorbing polymer and non-adsorbing crosslinking agent. The gelation process depends mainly on gelation time and the reaction rate.

\subsection{Gelation Time}

Gelation time can be defined as the time it takes for the injected solution to gel (when viscosity starts to increase). It depends on the reaction rate of the gel [23]. The start of gelation can be recognized as the inflection point on the viscosity versus time curve. Gelation time is a function of the concentration of polymer and crosslinker, temperature of the reservoir, and salinity and $\mathrm{pH}$ of the formation water. Gelation time can be increased by using low polymer concentration, which produces weak gel that is capable of penetrating deep into thief zones. On the other hand, gelation time decreases with increasing the concentration of the crosslinker [24]. For in-depth gel treatment, a long gelation time is required. On the contrary, a short gelation time is required for near-wellbore gel treatment. In the latter case a high concentration of polymer and crosslinker is used to form a strong gel that is suitable for blocking high permeability layers without crossflow. Therefore, accurate estimation of the gelation time is vital for the success of deep gel placement. Because, a too short gelation time may results in pre-mature gelation of the gel system. On the other hand, a too long gelation time may result in the production of the gel system from the producer where even the gelation process could not take place.

\subsection{Reaction Rate}

The reaction rate is the speed of the reaction [23]. A simplified reaction scheme for gel formation might be modeled by assuming the reaction is of the form that shown in Eq. (1):

$$
\text { polymer }(C 1)+\text { Crosslinker }(C 2) \rightarrow \text { Gel }(C 3)
$$

Where $\mathrm{C} 1, \mathrm{C} 2$, and $\mathrm{C} 3$ refer to the mass concentrations in the aqueous phase [25]. Reaction rates are characterized through the frequency factor (the rate constant) in CMGSTARS simulator [26]. The concentration of polymer is taken to decline according to a first order reaction scheme [27], as in Eq. (2):

$$
K=\frac{\ln (2)}{\tau_{1 / 2}}
$$

Where $K$ represent the first order rate constant, and $\tau_{1 / 2}$ is the half-life of the component (i.e., polymer and crosslinker). In modeling the reaction of polymer/crosslinker to form gel, it is assumed that both components are in stoichiometric ratios. Moreover, the time taken for the conversion of half of these components is given by second order reaction [25], as follows:

$$
K=\frac{5 * 10^{7}}{\tau_{1 / 2}}
$$


As a summary, the reaction rate is affected by the concentration of the reactants and the order of reaction. A reaction occurs mainly because of the collisions between the molecules of the reactants. Increasing the concentration of the reactants would result in more collisions of molecules and thereby a faster reaction is obtained.

\subsection{Gel Kinetic Model in STARS (Reaction Kinetics)}

As discussed previously, the gel modeling in STARS depends on the interaction of chemicals and the injected fluid which should contain adsorbing polymer and non-adsorbing crosslinker agent. The reaction kinetics in CMG-STARS simulator [26] is given by:

$$
\begin{gathered}
r_{k}=k \prod_{i=1}^{n_{c}} C_{i}^{e_{k}} \\
k=r_{r k .} e^{-\frac{E_{a}}{R T}}
\end{gathered}
$$

Substituting Eq. (5) in Eq. (4), yields:

$$
r_{k}=r_{r k .} e^{-\left(\frac{E a}{R T}\right)} \cdot \prod_{i=1}^{n_{c}} C_{i}^{e_{k}}
$$

Note that the definitions of all parameters are available in the nomenclature section at the end of this article.

Eq. (6) demonstrate that the reaction rate is affected by the reactants' concentration and the order of reaction. A reaction occurs mainly because of the collisions between the molecules of the reactants. Increasing the concentrations of the reactants would result in more collisions of molecules and thereby a faster reaction is obtained. In CMG-STARS simulator [26], Eq. (6) is used to model the creation of gel and Table 1 shows the representation of these variables as a keyword in STARS.

Table 1. Keywords connected to gel modeling in CMG-STARS simulator [26].

\begin{tabular}{ll}
\hline Variables in Eq. (6) & Keyword in STARS \\
\hline$e_{k}$ & RORDER \\
$r_{r k}$ & FREQFAC \\
$E_{a}$ & EACT \\
\hline
\end{tabular}

\subsection{Resistance Factor \& Residual Resistance Factor}

Mobility reduction, because of polymer flooding, can be quantified using a 'mobility reduction factor', otherwise known as the 'resistance factor' [28] and can be expressed as:

$$
R F=\frac{k_{w} / \mu_{w}}{k_{p} / \mu_{p}}=\frac{\text { Mobility of flooding water }}{\text { Mobility of polymer or gelant }}
$$

Resistance factor is equivalent to the effective viscosity of the gelant in porous media relative to that of water [29]. On the other hand, the permeability reduction as a result of polymer flooding and/or gel treatment can be quantified using a 'permeability reduction factor', otherwise known as 'resistance residual factor' [28]. The residual resistance factor can be expressed as $[28,30,31]$ :

$$
R R F=\frac{\left(\frac{k_{w}}{\mu_{w}}\right)_{\text {initial }}}{\left(\frac{k_{W}}{\mu_{w}}\right)_{\text {final }}}=\frac{\text { Initial Water Mobility Before Treatment }}{\text { Final Water Mobility After Treatment }}
$$

The permeability reduction factor or RRF is related to the adsorption level as given in Eq. (9). The mobility of water phase is divided by $R K_{w}$, thus accounting for blockage [26]:

$$
R K_{w}=1.0+(R R F-1.0)\left(\frac{A d s_{i}}{A d s_{\max }}\right)
$$

As mentioned previously, the residual resistance factor in low-permeability layers is higher than that in the thief zones. The latter assumption reflects the fact that low-permeability layers will have higher blocking and there will be a severe damage if gel enters or formed in these layers [25].

\section{Building the Model}

\subsection{Description of the Model}

A $3 \mathrm{D}$ representation of the model was presented in Figure 1 and the wells are completed through all layers. The selected pattern will maximize the production rate because it has a higher ratio of producer to injector. The model dimensions were $1170 \times 1170 \times 164 \mathrm{ft}^{3}$ with $30 \times 30 \times 3$ gridblocks. The size of each gridblock was 39 feet and the thickness of the layers were different as shown in Table 2 .

Two rock types were considered: rock type 2 for layers 1 and 2 (i.e., the thief zones), in which a linear dependence relative permeability was assumed and rock type 1 for layer 3 as shown in Figure 2. In addition, Table 3 shows the basic parameters of the reservoir, while Table 4 shows the fluid properties. In this study, the injection rate was 1,070 barrels per day for all runs and the models were run for 25 years. Table 5 represent the properties of the polymer solution, while Table 6 represent the properties of gel. Other considerations were:

1. All fluids are incompressible.

2. Only water and oil phases were considered and gas phase was not considered.

3. No aquifer was attached to the model, the injected water was from the injection well only.

4. The model is isothermal (activation energy is not required).

5. Polymer exists in the water phase.

6. Chemical reactions only occur between polymer and crosslinker.

7. Water density does not affected by polymer.

8. No biological degradation is modeled since synthetic polymer (i.e., HPAM) is less susceptible to biological attack.

9. The injection of chemicals was started at $80 \%$ water cut 


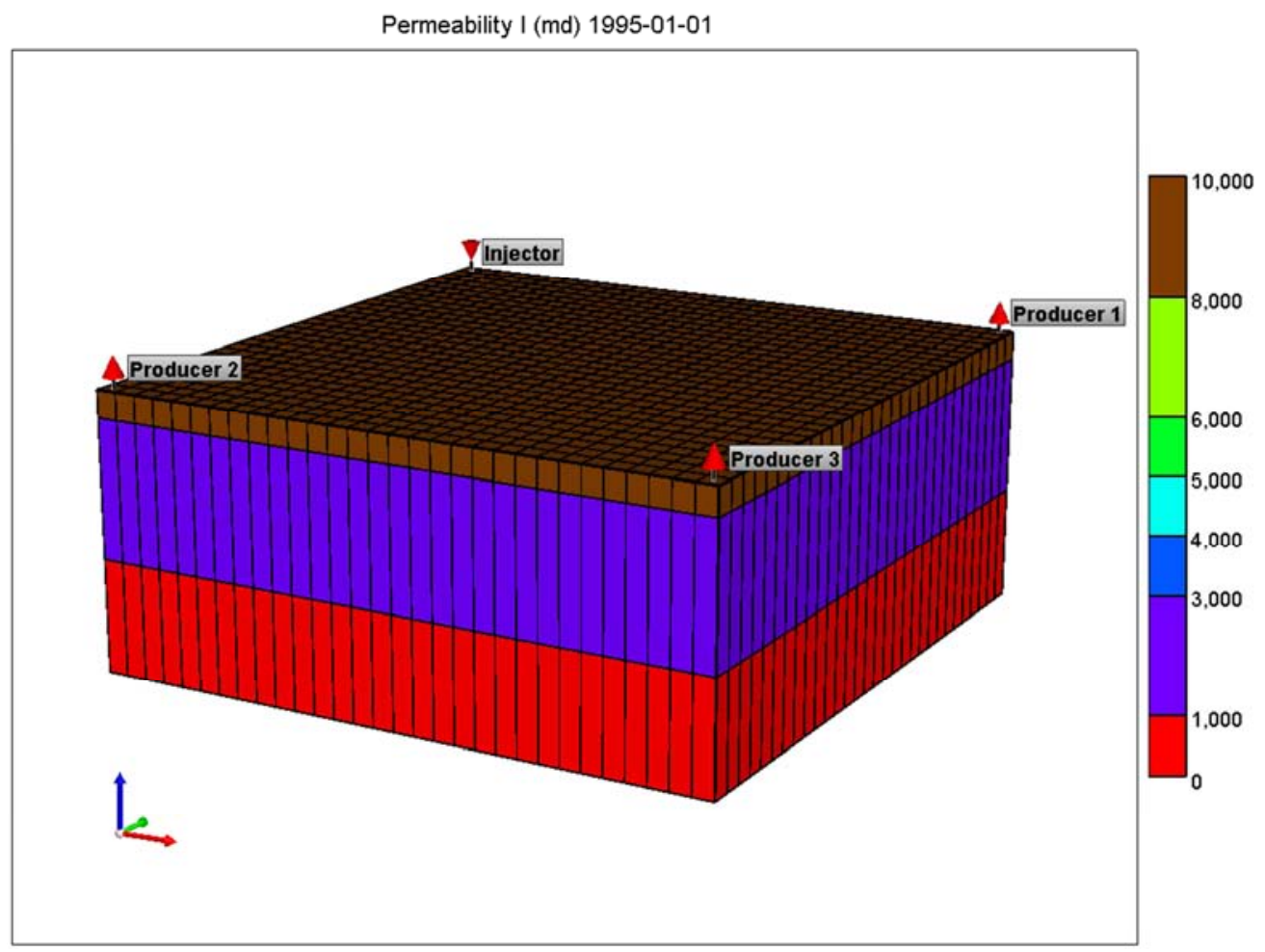

Figure 1. 3D visualization of the model.

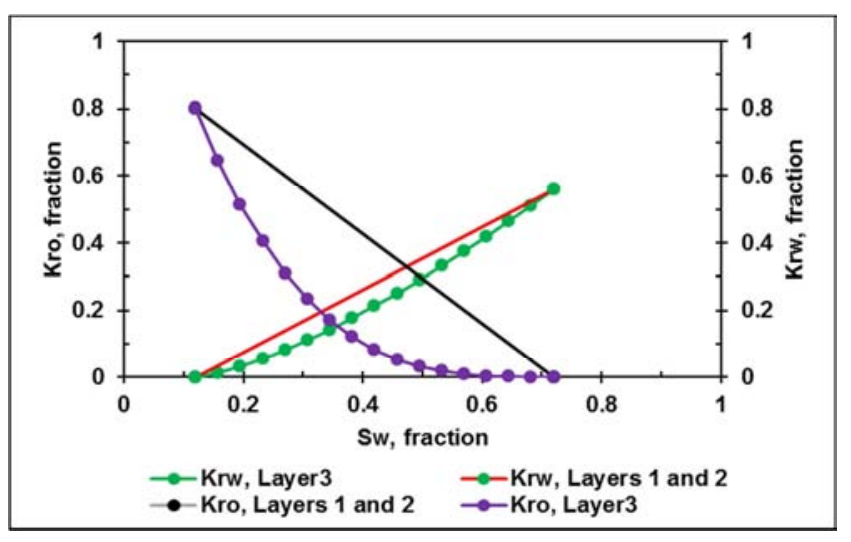

Figure 2. Water and oil relative permeability curves [25].

Table 2. Basic parameters of the model [32].

\begin{tabular}{llll}
\hline Layer & Thickness (ft.) & Porosity (\%) & Permeability (mD) \\
\hline 1 & 16 & 32 & 10,000 \\
2 & 82 & 30 & 2000 \\
3 & 66 & 28 & 780 \\
\hline
\end{tabular}

Table 3. Basic parameters of the reservoir [32].

\begin{tabular}{ll}
\hline Reservoir temperature & $149^{\circ} \mathrm{F}$ \\
Initial reservoir pressure & $2031 \mathrm{psi}$ \\
$\mathrm{K}_{\mathrm{v}} / \mathrm{K}_{\mathrm{h}}$ & 0.1 \\
Initial water saturation & 0.22 \\
Rock type 1 & Layer 3 \\
Rock type 2 & Layers 1 and 2 \\
\hline
\end{tabular}

Table 4. Fluid properties.

\begin{tabular}{ll}
\hline Water viscosity and density & $0.6 \mathrm{cp}, 62.4 \mathrm{lb} / \mathrm{ft}^{3}$ \\
Oil viscosity and density & $78.0 \mathrm{cp}, 59.31 \mathrm{lb} / \mathrm{ft}^{3}$ \\
Polymer viscosity and density & $30.0 \mathrm{cp}, 62.4 \mathrm{lb} / \mathrm{ft}^{3}$ \\
\hline
\end{tabular}

\begin{tabular}{ll}
\hline Crosslinker viscosity and density & $30.0 \mathrm{cp}, 62.4 \mathrm{lb} / \mathrm{ft}^{3}$ \\
Polymer molecular weight & $18,000 \mathrm{lb} / \mathrm{lbmole}$ \\
Crosslinker molecular weight & $206 \mathrm{lb} / \mathrm{lbmole}$ \\
CDG molecular weight & $18,206 \mathrm{lb} / \mathrm{lbmole}$ \\
Polymer concentration & $1,000 \mathrm{ppm}$ \\
Crosslinker concentration & $20 \mathrm{ppm}$ \\
\hline
\end{tabular}

Table 5. Properties of polymer solution [32].

\begin{tabular}{|c|c|c|c|}
\hline $\begin{array}{l}\text { Polymer conc., } \\
\text { wt. } \%\end{array}$ & Viscosity, cp & $\begin{array}{l}\text { Adsorption density, } \\
\mathbf{l b} / \mathbf{f t}^{3}\end{array}$ & Frr \\
\hline 0 & 0.6 & 0 & 1.0 \\
\hline 0.04 & 12.2 & 20.5 & 1.6 \\
\hline 0.08 & 26.4 & 35.1 & 2.1 \\
\hline 0.12 & 34.5 & 40.8 & 2.6 \\
\hline
\end{tabular}

Table 6. Properties of gel [32].

\begin{tabular}{lll}
\hline Polymer conc., wt.\% & Retention density, $\mathbf{m g} / \mathbf{l}$ & Frr \\
\hline 0.0 & 0 & 1 \\
0.04 & 400 & 4 \\
0.08 & 800 & 12 \\
0.12 & 1200 & 28 \\
\hline
\end{tabular}

\subsection{Injection of Colloidal Dispersion Gel}

CDG is injected by two methods:

1. Sequential injection: this process includes an alternative injection of long-term slug of polymer and short-term slug of crosslinker [6].

2. Simultaneous injection: the polymer and crosslinker are injected at the same time (i.e., concurrent or coinjection) and the gel is formed at a fixed time [1].

In this study, we modeled the injection of CDG based on the simultaneous injection method. The field experience proved that when using the sequential injection method, the 
polymer and crosslinker might not come together at the same time inside the thief zones, which leads to the failure of the treatment.

\subsection{Injection Schedules}

The injected volumes of CDG are measured by pore volumes and can be compared with polymer flooding. Therefore, CDG is a flooding operation rather than treatment. In the Loma Alta Sur field in Argentina, the total volume of the injected CDG is 391,094 barrels, which represents 3.06\% of the pore volume of the LAS-58 pilot area [33]. In the Daqing oil field, they injected $0.53 \mathrm{PV}$ of chemical slugs (0.18 PV CDG, 0.15 PV polymer, and 0.2 PV CDG) over a period of four years (i.e., 0.14 PV/yr.) [8]. In this study, the total injected volumes of CDG was $1,177,000$ barrels within three years, which represented 0.10 of the total PV. Thus, the longtime of the CDG injection was based on the previous field applications. Two methods of placing the gelant solution are normally used: bullhead and zonal isolation. In the bullhead method, the gelant solution has access to all three layers without isolation, while in zonal isolation method the gelant solution has access to layers 1 and 2 only.

\section{Results and Discussions}

\subsection{Comparison Between Polymer and CDG Flooding}

The success of any gel treatment depends on the recovery factor and sweep efficiency before applying the treatment
[34]. In this study, a thick heterogeneous reservoir, with crossflow between layers and high oil viscosity, was considered. It seems from Table 7 that the recovery factor obtained from water flooding was $27.8 \%$ only. Therefore, applying gel treatment should improve the sweep efficiency from the reservoir. The purpose of injecting the polymer solution is to reduce the high mobility ratio, whereas the purpose of injecting gel is to reduce or block off the highpermeability layers. However, CDG and polymer flooding share multiple similarities; yet, oil production response occurred immediately during the polymer flooding and the oil production declined slowly after the treatment. During CDG flooding, the increase in the oil production rate lasted much longer [35]. Moreover, the oil recovery by polymer flooding from flooded-out layers is insignificant [31].

The aim of this comparison is to prove that CDG is more preferable than uncrosslinked polymer flooding and to prove that the residual resistance factor (RRF) generated by CDG is higher compared to RRF from the polymer solution only. This comparison will determine the technical feasibility of implementing CDG injection in field applications. The same pore volume (i.e., 0.1 ) of polymer solution is injected into all three layers without zonal isolation. Table 7 show a large difference between polymer flooding and CDG flooding, while Figure 3 compares RRF between polymer flooding (left) and CDG injection (right), which proves that CDG yielded RRFs 4-5 times higher than uncrosslinked polymer. Thus, CDG must be used to block this thief zone and divert subsequent water injection into the low-permeability layer.

Table 7. Recovery factor and incremental oil from polymer and CDG flooding.

\begin{tabular}{|c|c|c|c|c|c|c|}
\hline Scheme & RF, \% & $\begin{array}{l}\text { Cum. oil, MM } \\
\text { STB }\end{array}$ & $\begin{array}{l}\text { Incremental oil, } \\
\text { MM STB }\end{array}$ & $\begin{array}{l}\text { Water cut during the } \\
\text { treatment }\end{array}$ & Final water cut & Max. RRF \\
\hline WF & 27.80 & 2.55 & & & 94.5 & \\
\hline Polymer Flooding & 29.30 & 2.69 & 0.14 & 83.0 & 94.5 & 1.62 \\
\hline $\mathrm{CDG}$ & 40.30 & 3.70 & 1.15 & 40.0 & 90.6 & 7.80 \\
\hline
\end{tabular}
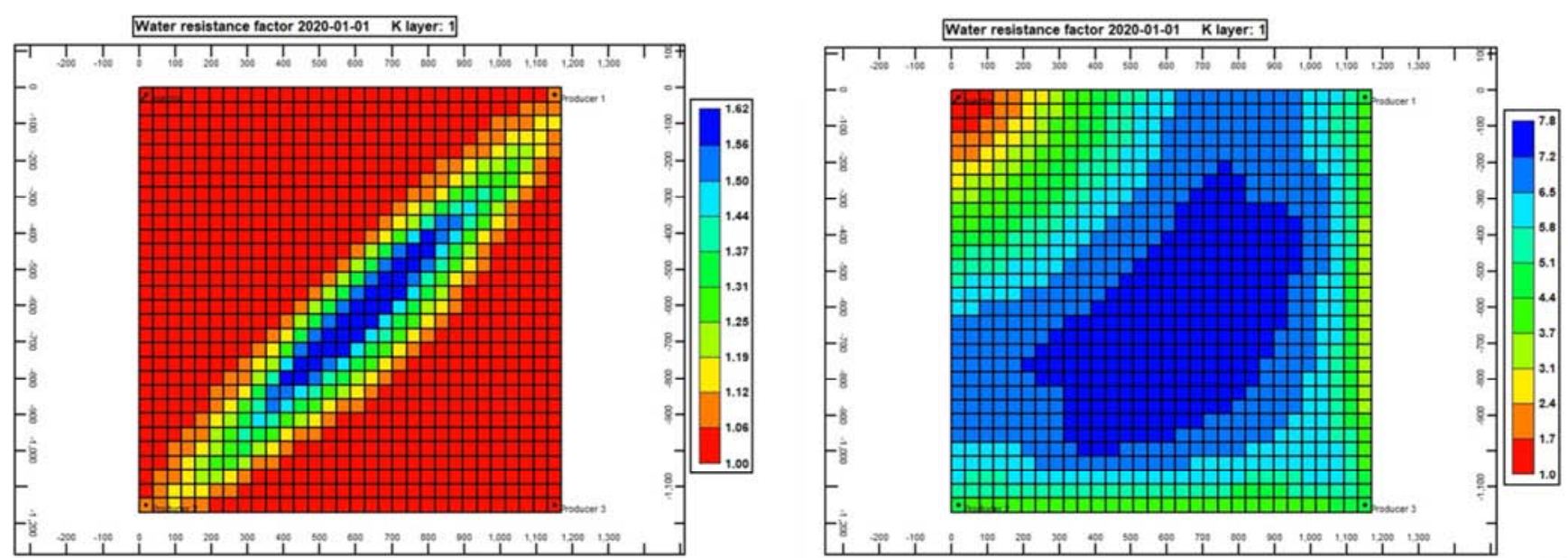

Figure 3. Comparison of water residual resistance factor between polymer (left) and CDG (right).

\subsection{Effect of Shear-Thinning Behavior of CDG on the Selective Penetration}

There is always a debate regarding the ability of CDG to enter the thief zones without damaging the low-permeability layers. If the gel treatment is performed in unfractured wells (i.e., radial flow), the zonal isolation is more likely to be needed [36-38]. However, if the gelling agent has a water- 
like viscosity and the resistance factor is unity, minimum damage to the low-permeability layers could happen because the low viscosity fluids penetrate less into the lowpermeability layers [37]. Thus, mechanical isolation is the most effective way of protecting the low-permeability layers during gelant solution placement. Moreover, the bullhead injection will always cause a damage to the less permeable layers.

Shear-thinning fluids such as CDG or xanthan-based polymer gels might have a higher tendency to flow in the high-permeability layers due to the lower viscosity near the wellbore, which provides more favorable injectivity [6, 39, 40]. Thus, the shear-thinning behavior could assist the

placement of CDG solution without the necessity of zonal isolation (i.e., mechanical packer). In order to show the effect of shear-thinning behavior of the placement of CDG, two scenarios were considered where CDG was injected using the bullhead method. In the first scenario, the shear rate was not considered to have any effect on the viscosity of CDG, which is a hypothetical assumption, whereas in the second model, a real CDG rheology model was considered (i.e., shearthinning behavior). Table 8 shows the incremental oil achieved by the shear-thinning model, which assisted the gelant solution to enter and block the thief zones only (Figure 4).

Table 8. Effect of shear thinning on selective penetration.

\begin{tabular}{llll}
\hline Scheme & Rheology & RF, $\%$ & Cum. oil, MM STB \\
\hline WF & & 27.80 & 2.55 \\
CDG & Shear rate effect is not considered & 39.08 & 3.58 \\
CDG & Shear-thinning behavior & 39.50 & 3.62 \\
\hline
\end{tabular}

When shear-thinning behavior of CDG is considered, layer 3 (the less permeable layer in this model) is not affected by gelant solution placement even when gelant has access to all open layers as shown in the left-hand side of Figure 4. Therefore, shear-thinning rheology of the CDG, supported by the difference of saturation of the fluids in heterogeneous reservoir's model, can further assist CDG to penetrate

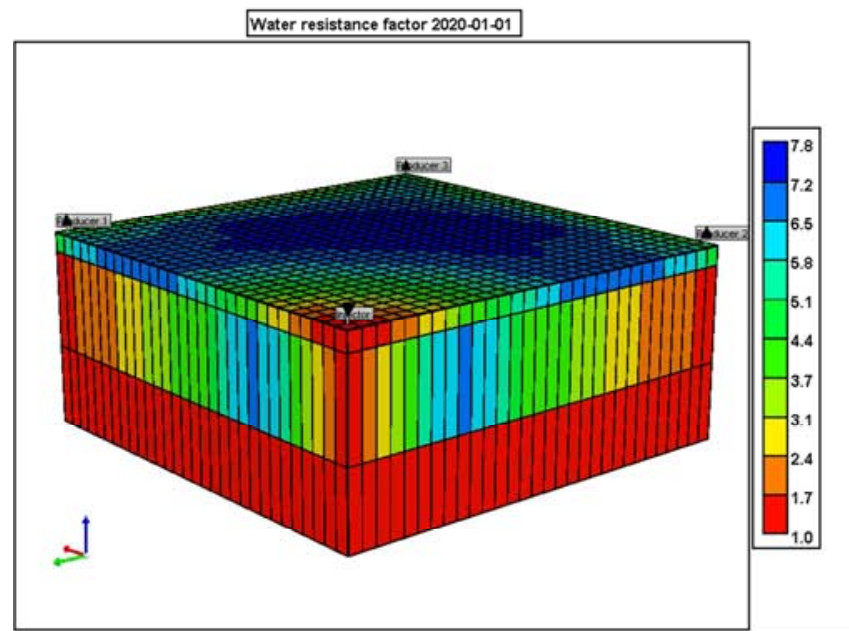

selectively into low-permeability layers. These results confirmed the ability of shear-thinning gelant solution to penetrate into thief zones without damaging the less permeable layer; thus, reducing the cost of mechanical isolation of the low-permeability layer. However, the maximum residual resistance factor was higher when the shear-thinning rheology model was not considered.

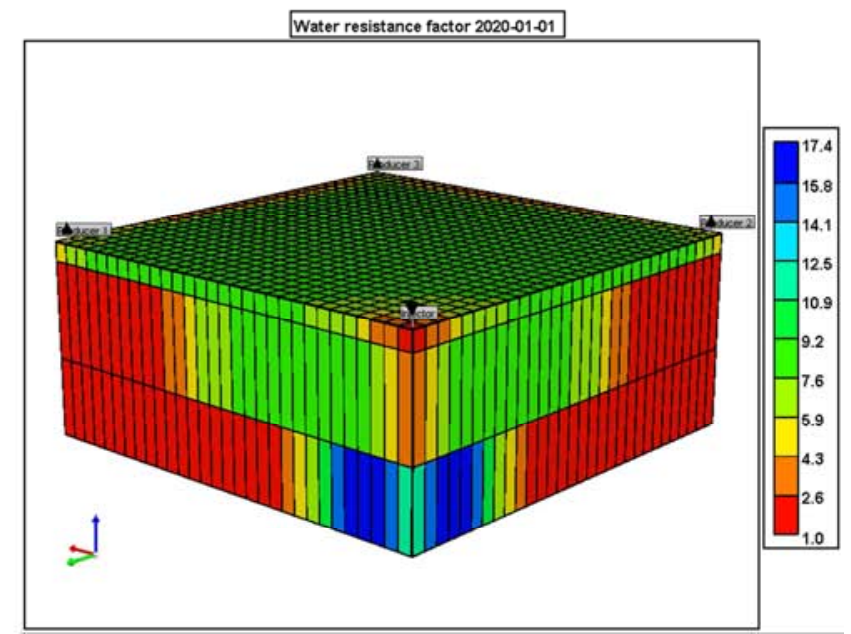

Figure 4. Damage in layer 3 when shear-thinning behavior is not considered (right) compared to no-damage in this layer when shear-thinning model is considered (left).

\subsection{Effect of CDG Adsorption}

Polymer, which is the main component of any gel system, has three types of retention when it flows inside the porous media. These mechanisms are adsorption, mechanical entrapment, and hydrodynamic retention [41]. Mechanical entrapment is irreversible and happens when the large polymer molecules are trapped in pores with small exit porethroat diameter. The polymer propagation, and hence gel propagation, is significantly affected by mechanical entrapment if the pore-throat sizes are too small [42]. In this study, mechanical entrapment is not important because the permeability was too high. The hydrodynamic retention is reversible and occurs when flow rates are suddenly increased. Thus, polymer adsorption is the most important mechanism, which is defined as the adhesion of the polymer molecules onto the rock surfaces [43]. A recent study suggested that the permeability reduction caused by polymer flooding might not be the same after post-treatment water injection and the performance of the reservoir after the treatment might be exaggerated [44]. In addition, the permeability reduction caused by $\mathrm{CDG}$ injection could be removed with prolonged injection of chase water [9]. Thus, to prove whether permeability reduction generated by $\mathrm{CDG}$ 
injection could be removed or not, three assumptions for adsorption were suggested. Therefore, three models with irreversible, partially reversible, and reversible adsorptions were considered. The results shown in Table 9 suggest that assuming irreversibility of polymer adsorption will give higher results compared to other options (i.e., partial reversible and reversible adsorption).

Table 9. Recovery factor and cumulative oil for different degrees of adsorption.

\begin{tabular}{lllll}
\hline Scheme & Adsorption & RF, $\%$ & Cum. oil, MM STB & Incremental oil, MM STB \\
\hline WF & & 27.80 & 2.55 & \\
CDG & Reversible & 36.11 & 3.31 & 0.76 \\
CDG & Partial Reversible & 37.00 & 3.40 & 0.85 \\
CDG & Irreversible & 40.25 & 3.70 & 1.15 \\
\hline
\end{tabular}

To show if the permeability reduction caused by the gel treatment will vanish and be removed as concluded by other researchers [9, 44], an extension of post-treatment water injection until year 2050 was considered (the default end date of the simulation run was 2020). Figure 5 (left-hand side)

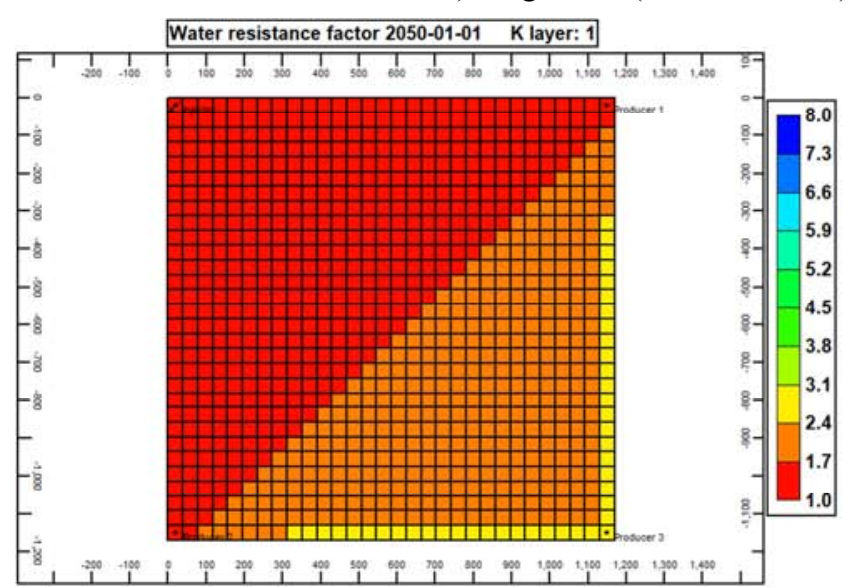

shows that after prolonged injection of post-treatment water for the reversible adsorption model, there was still permeability reduction in the thief zone (layer 1) and the gel treatment was not removed completely.

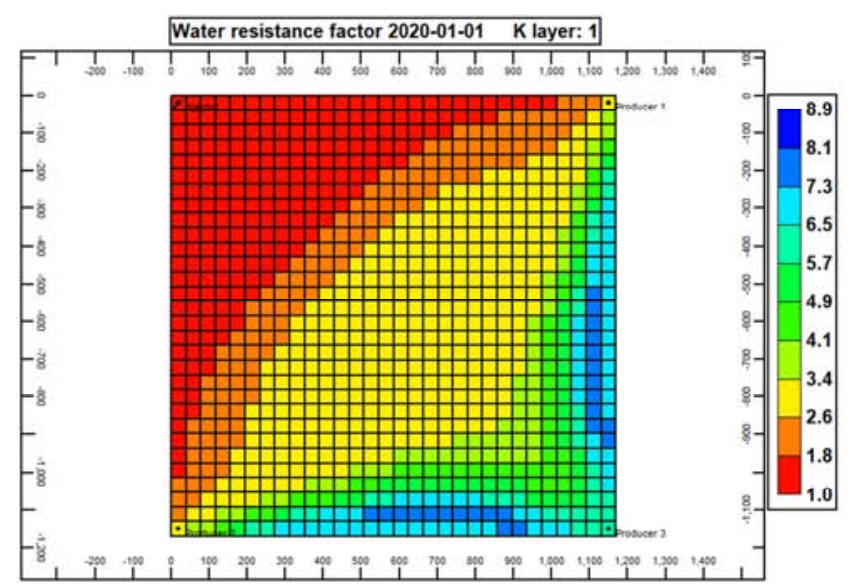

Figure 5. Comparison of water residual resistance factor in layer 1 between prolonged injection (left) and default run (right).

\subsection{Effect of CDG Degradation}

\subsubsection{Chemical Degradation}

Gel degradation is related in one way or another with polymer degradation. Polymer solutions such as HPAM and xanthan are subjected to thermal, microbial, mechanical, and chemical degradations. However, HPAM polymer solution is relatively more tolerant to microbial (bacterial) attack than xanthan biopolymer solution. On the other hand, the presence of oxygen and other contaminants such as iron is considered the main cause of chemical degradation [1].

In this section, a gel degradation time was used to represent the chemical degradation. The gel degradation time refers to the time at which gel viscosity is same as water viscosity and it has no effect on blocking the permeability of the thief zones [32]. Four scenarios were modeled, which include no degradation, 1-year, 2-year, and 4-year gel degradation. Table 10 shows the difference in recovery factors and incremental oil. The longer the gel degradation time, the lower the chemical degradation, the higher the recovery factor, the higher the residual resistance factor, and the deeper the gel can penetrate into the thief zone. Figure 6 shows how far CDG can penetrate deep into layer 1 when there is no gel degradation compared to 1,2 , and 4 year degradation time.

Table 10. Recovery factor and cumulative oil under different chemical degradation times.

\begin{tabular}{llllll}
\hline Scheme & Degradation & RF, \% & Cum. oil, MM STB & Incremental oil, MM STB & Max. Frr \\
\hline WF & & 27.80 & 2.55 & & \\
CDG & Nil & 40.25 & 3.70 & 1.15 & 9.0 \\
CDG & 1 year & 34.19 & 3.13 & 0.58 & 3.5 \\
CDG & 2 year & 37.72 & 3.46 & 0.91 & 4.4 \\
CDG & 4 year & 38.62 & 3.54 & 0.99 & 5.3 \\
\hline
\end{tabular}



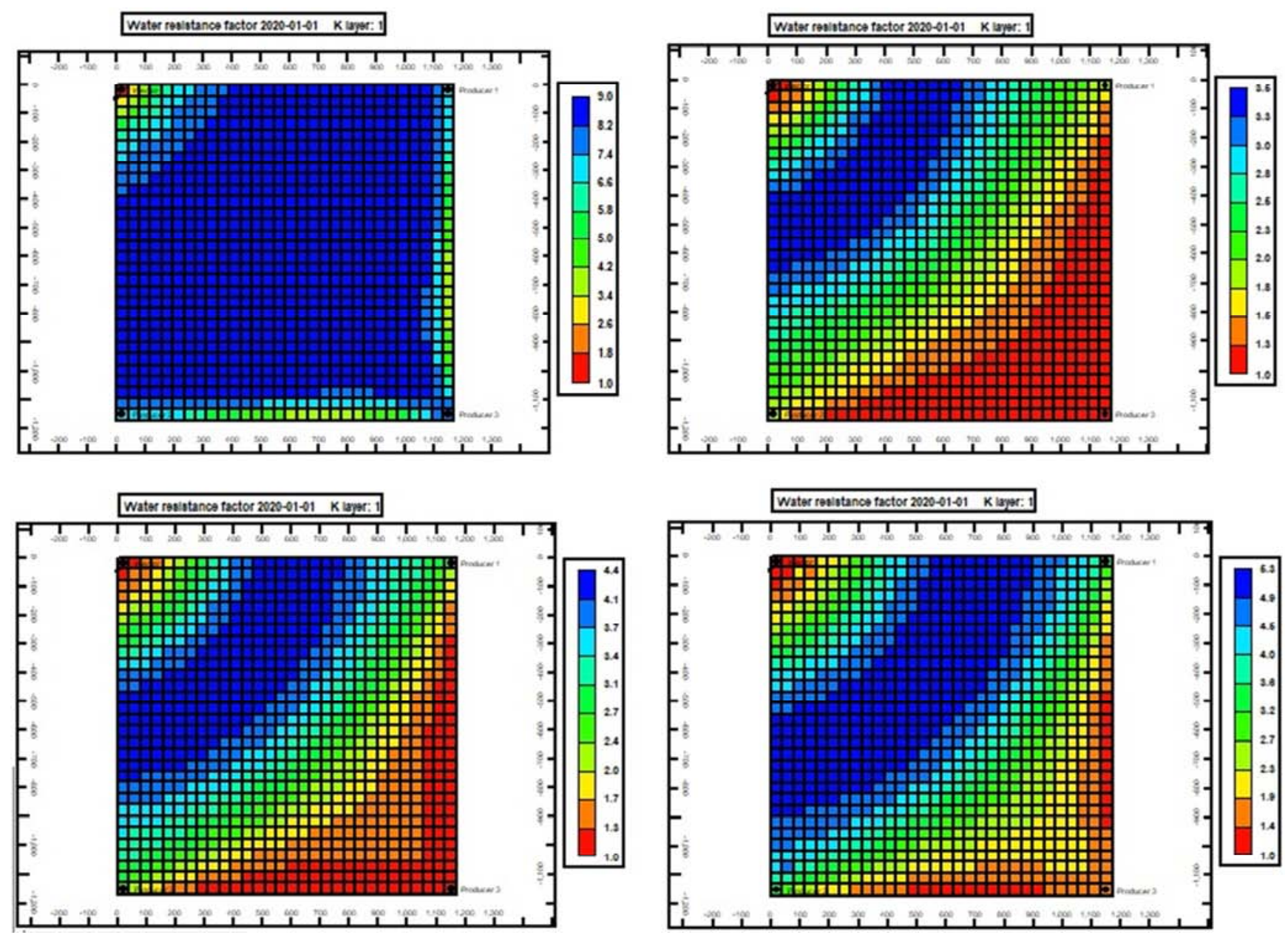

Figure 6. Comparison of water residual resistance factor in layer 1 between no degradation (upper left), 1-year (upper right), 2-year (lower left), and 4-year degradation (lower right).

\subsubsection{Mechanical Degradation}

Flow of polymer and gelant solutions through restricted areas such as valves, pumps, pore throats, and perforations is the main factor that initiates the mechanical (shear) degradation. Mechanical degradation occurs when the shear rate is increased above the critical shear rate of the polymer (i.e., polymer stretch rate) $[45,46]$. This degradation depends on the molecular weight of the polymer, therefore the higher the molecular weight the longer the molecule chain and the higher the degradation rate [47-49]. Thus, long chains are subjected to cut through its center, which leads to decrease of polymer viscosity and eventually poor sweep efficiency. Two investigators [50] developed a model to calculate polymer viscosities as a function of shear rate taking into account the effect of mechanical degradation, which uses molecular weight distributions of the polymer solution, as shown in Figure 7. These data were used, modeled, and compared to show the effect of mechanical degradation on the propagation of the CDG.

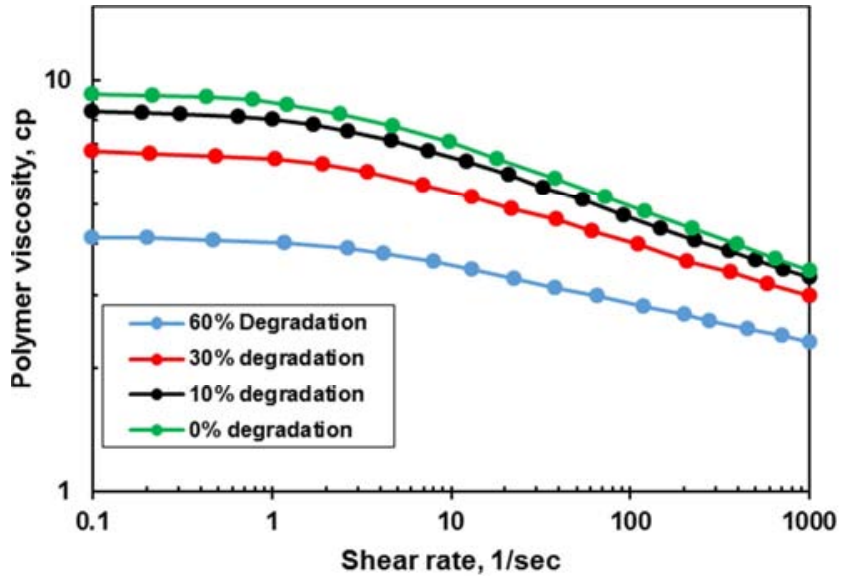

Figure 7. Polymer viscosity vs. shear rate at different levels of degradation $[50]$.

In our model, the pore throats are large because of the high permeability of the thief zones. However, the polymer solution is still subject to mechanical degradation because of the existence of the restricted areas, as mentioned previously. It is obvious from Table 11 and Figure 8 that water saturation was distributed more evenly in layer 1 for $0 \%$ and $10 \%$ mechanical degradation than for $30 \%$ and $60 \%$ cases. The 
latter findings proved that CDG has higher strength in $0 \%$ and $10 \%$ degradations than in $30 \%$ and $60 \%$ degradations.

Table 11. Recovery factor and cumulative oil under different mechanical degradation criteria.

\begin{tabular}{lllll}
\hline Scheme & Degradation & RF, $\%$ & Cum. oil, MM STB & Incremental oil, MM STB \\
\hline WF & & 27.80 & 2.55 & 1.05 \\
CDG & $0 \%$ & 39.00 & 3.60 & 1.00 \\
CDG & $10 \%$ & 38.66 & 3.55 & 0.95 \\
CDG & $30 \%$ & 37.99 & 3.50 & 0.85 \\
CDG & $60 \%$ & 37.09 & 3.40 & \\
\hline
\end{tabular}
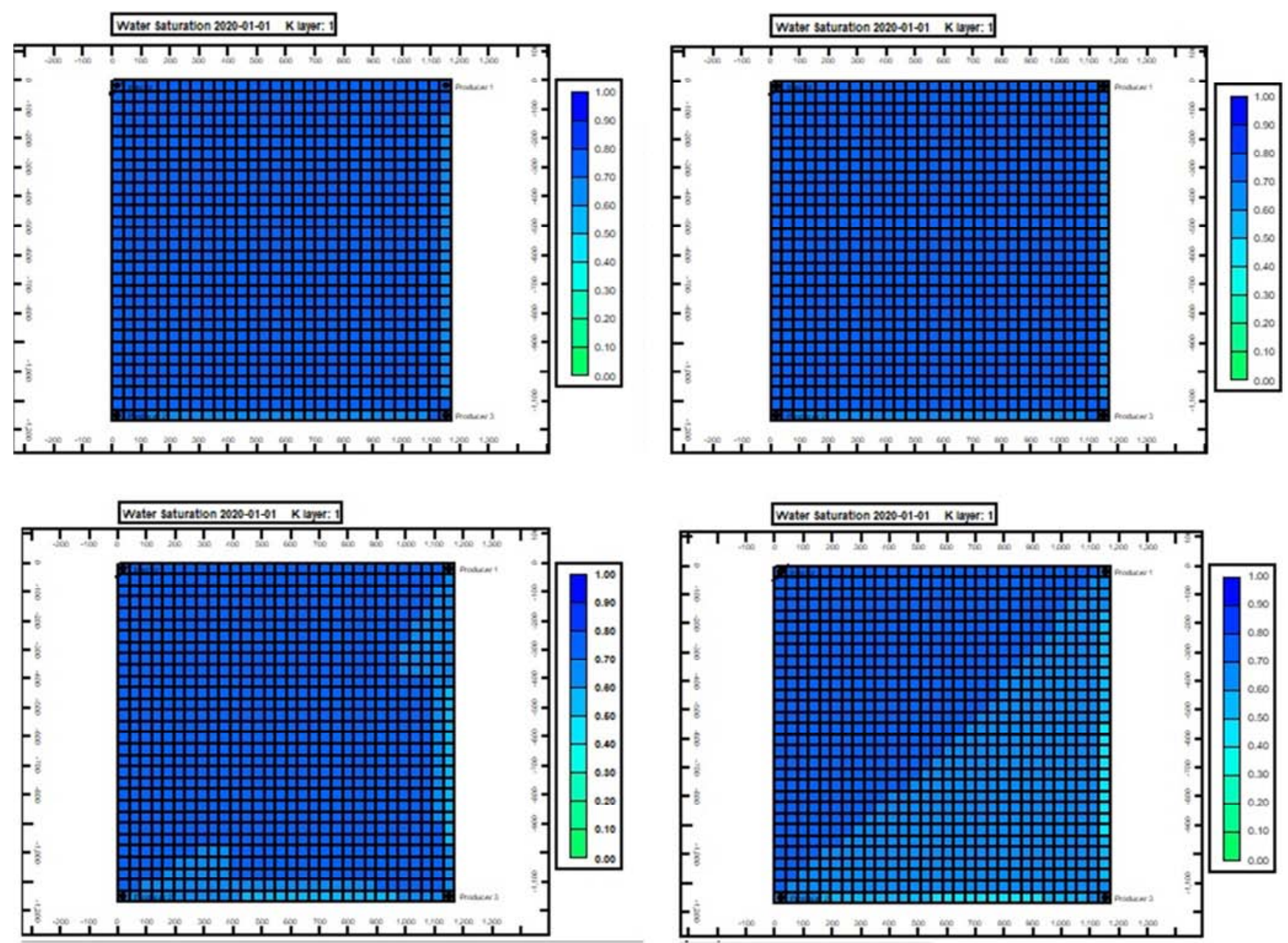

Figure 8. Comparison of water saturation in layer 1 between $0 \%$ (upper left), 10\% (upper right), 30\% (lower left), and $60 \%$ mechanical degradation (lower right).

\subsection{Effect of Salinity on the Performance of CDG}

In field applications, the long history of water injection make the reservoir brine salinity similar to the salinity of the injected water before the initiation of injection of any chemicals [51]. In addition, the makeup water and/or the reservoir brine that is used to prepare the treatment have an effect on the performance of the chemical enhanced oil recovery processes. As mentioned previously, the strength of CDG decreases as the salinity increases. A previous study suggested that the CDG can tolerate a water salinity up to $30,000 \mathrm{mg} / \mathrm{l}$ without any problems [6]. However, a recent screening criteria suggested that CDG could tolerate between $3,000 \mathrm{mg} / \mathrm{l}$ to $130,000 \mathrm{mg} / \mathrm{l}$ of water salinity in the field applications [52]. Hence, in order to demonstrate the effect of salinity on CDG, the effect of salinity on the viscosity of HPAM polymer solution should be investigated. Sheng (2011) stated, "An HPAM flexible chain is compressed in saline water, resulting in low viscosity" (Ch. 5, page no. 106). This is because when the salinity is high, the polymer molecules tend to compact due to the loss of water to the more saline environment that surround the solution [53]. However, at low salinities, polymer molecules tend to stretch, which causes high polymer viscosity. Several researchers $[54,55]$ presented data of polymer viscosity versus polymer concentration and shear rate at different salinities, which was used in this section.

In the formulation of a $\mathrm{CDG}$, a range of polymer 
concentrations from $0.01 \mathrm{wt}$. $\%$ to $0.12 \mathrm{wt} \%$ polymer is used [1]. In all previous sections, a 0.10 wt. \% polymer concentration was used. Thus, a new model with a new polymer concentration (i.e., 0.12 wt. \%) was used with the same polymer to crosslinker ratio (i.e., 50/1).

The HPAM polymer solution was prepared using $\mathrm{NaCl}$ with different salinities that range from fresh water up to $30,000 \mathrm{mg} / \mathrm{l}$ salinity as shown in Figure 9 and these mixture were modeled individually with the specified polymer to crosslinker ratio. It is obvious that the higher the salinity of the makeup water, the lower the viscosity of the polymer solution. Consequently, this will affect the strength of the formed CDG, which lowers the sweep efficiency and permeability reduction in the thief zone as shown in Table 12 and Figure 10.

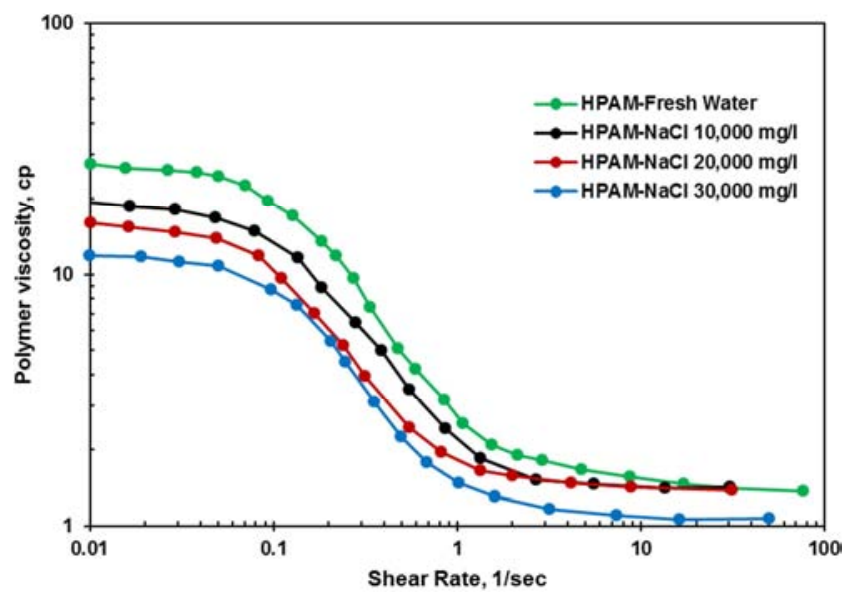

Figure 9. Polymer viscosity vs. shear rate at different levels of salinity [55].

Table 12. Recovery factor and cumulative oil under different salinities.

\begin{tabular}{|c|c|c|c|c|c|}
\hline Scheme & NaCl salinity, mg/l & RF, \% & Cum. oil, MM STB & Incremental oil, MM STB & Max. Frr \\
\hline WF & & 27.80 & 2.55 & & \\
\hline CDG & Fresh water & 40.90 & 3.75 & 1.20 & 8.9 \\
\hline CDG & 10,000 & 40.17 & 3.68 & 1.13 & 8.6 \\
\hline $\mathrm{CDG}$ & 20,000 & 39.46 & 3.62 & 1.07 & 8.5 \\
\hline $\mathrm{CDG}$ & 30,000 & 38.72 & 3.55 & 1.00 & 8.3 \\
\hline
\end{tabular}
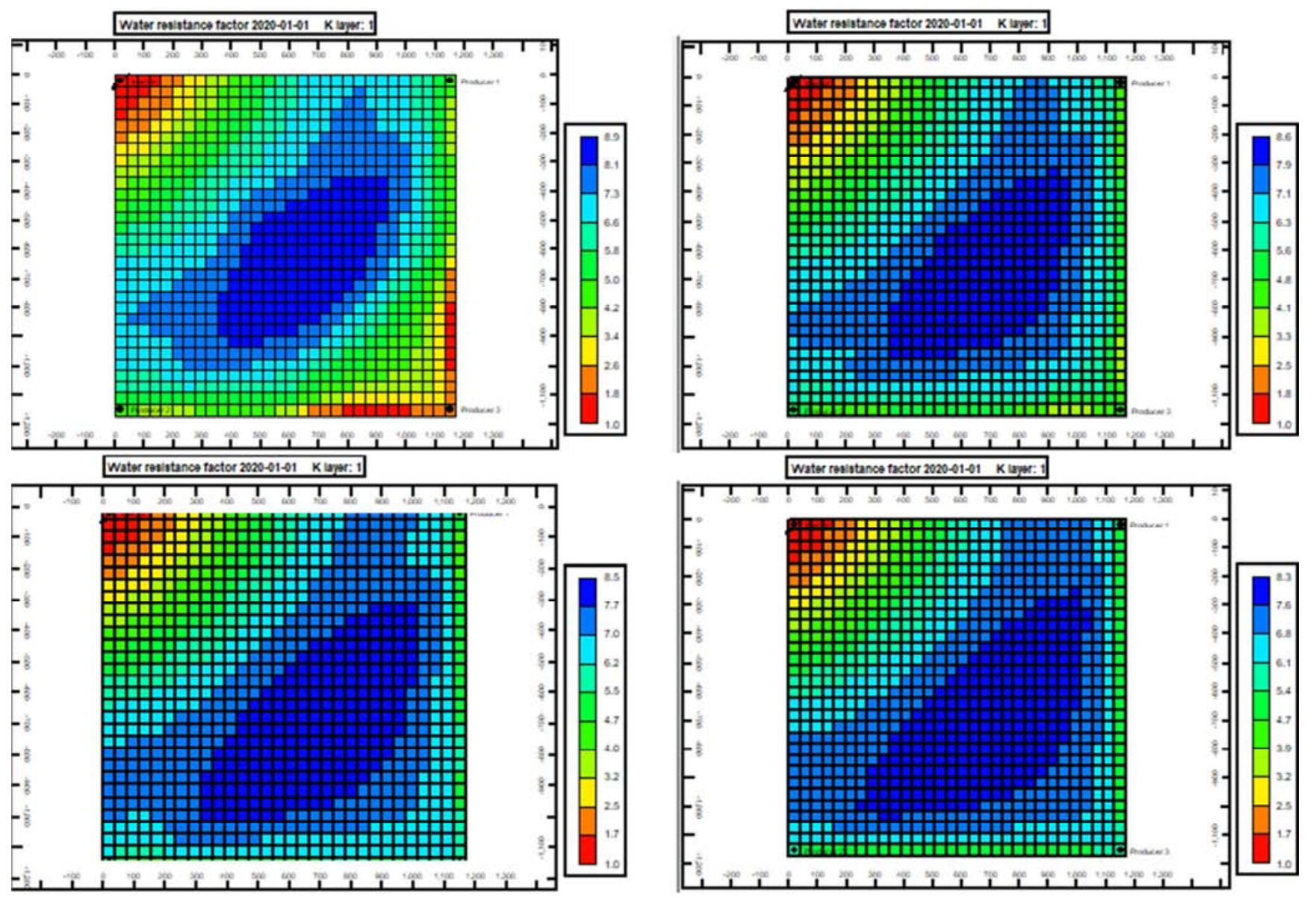

$\mathrm{HPAM}+$ fresh water (upper left), HPAM+10,000 mg/1 NaCl (upper right), HPAM+20,000 mg/l NaCl (lower left), and HPAM+30,000 mg/l NaCl (lower right).

Figure 10. Comparison of residual resistance factor in layer 1. 


\subsection{Comparison Between In-Depth and Near-Wellbore Gel Treatment}

When flooding a thick heterogeneous reservoir with crossflow between layers, it is imperative to inject the gelant solution to penetrate deep into the thief zones. Near-wellbore (NWB) treatment in the order of fifty feet is sufficient to reduce the permeability of layered reservoir without crossflow by a factor of 100 or more [56]. To demonstrate the importance of in-depth gel treatment for this type of reservoir, a near-wellbore (NWB) gel treatment is considered. During NWB gel treatment, high concentrations of polymer and crosslinker were used to form a strong gel, as compared to the deep fluid diversion method where low concentrations of the reactants were used to yield long

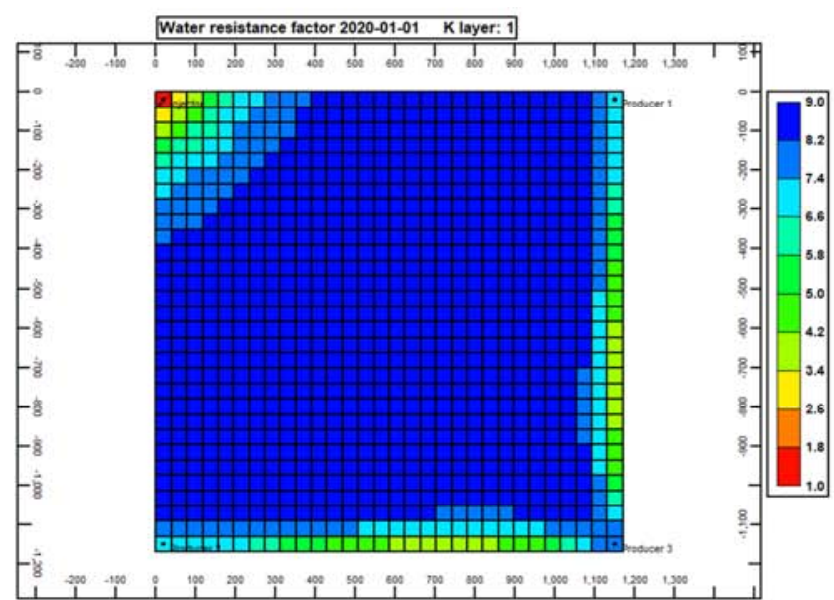

gelation time. If there was a crossflow, the post-treatment water injection could move around the gel and back into the thief zone with minimum impact on pattern performance as compared to in-depth treatment. Figure 11 shows the residual resistance factor in layer 1, which represents the depth of gel penetration by in-depth (left) and near-wellbore (right) treatments, while Table 13 shows a comparison between oil recovery and incremental oil between these two cases. Therefore, in NWB gel treatment the maximum residual resistance factor was 22.3, compared to 9.0 in case of indepth gel treatment; however, the effect of NWB gel treatment was limited to the cell around the injection well only. Thus, NWB gel treatment was not as efficient as indepth gel treatment.

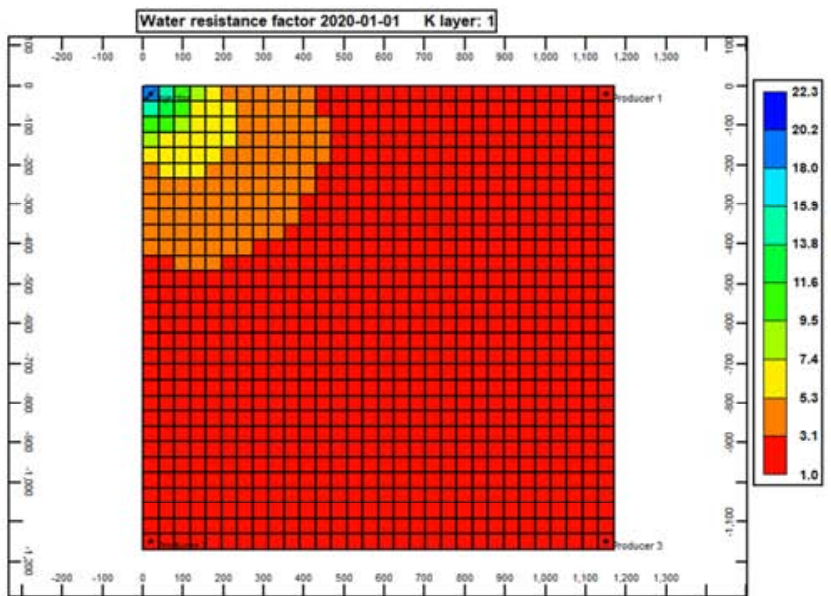

Figure 11. Comparison of residual resistance factor generated from in-depth (left) vs near-wellbore gel treatment (right).

Table 13. Comparison of recovery factor and cumulative oil between in-depth and NWB treatment.

\begin{tabular}{llllll}
\hline Scheme & Injected Fluid & PV, injected gel & RF, \% & Cum. oil, MM STB & Incremental oil, MM STB \\
\hline WF & & & 27.80 & 2.55 & 1.15 \\
CDG & In-depth & 0.1 & 40.25 & 3.70 & 0.45 \\
CDG & Near-wellbore & 0.1 & 32.76 & 3.00 & \\
\hline
\end{tabular}

\subsection{Effect of the Alternative Injection of CDG and Polymer}

To enhance the recovery from this heterogeneous thick reservoir with viscous oil, it would be preferable to inject polymer either before or after the treatment. The injected polymer slug size was $0.1 \mathrm{PV}$. Therefore, two scenarios were compared with CDG treatment alone. Table 14 shows the results of this comparison.

Table 14. Recovery factor and cumulative oil under combination injection of gel and polymer.

\begin{tabular}{lllll}
\hline Scheme & Sequence of the injection & RF, $\%$ & Cum. oil, MM STB & Incremental oil, MM STB \\
\hline WF & & 27.80 & 2.55 & 1.15 \\
CDG & Gel only & 40.25 & 3.70 & 1.37 \\
PF_CDG & Polymer-gel & 42.72 & 3.92 & 1.47 \\
CDG_PF & Gel-polymer & 43.81 & 4.02 & \\
\hline
\end{tabular}

As can be seen from this table, polymer injection with CDG flooding always yielded higher results regardless of the sequence of the injection. However, the injection of polymer solution after the injection of CDG was better than injection of polymer before the injection of CDG. The increase in recovery factor was attributed to the high degree of permeability reduction in the high-permeability layers, resulting from the interaction of polymer that followed the gel treatment with the unreacted crosslinkers.

\subsection{Effect of Reservoir Wettability on the Performance of CDG}

CDG or any other type of gel are composed of polymer, crosslinker, and additives where water represents more than 
$90 \%$ of these mixtures. Capillary forces, interfacial tension, and wettability of the reservoir rocks govern the distribution of fluids inside the reservoir [57]. Thus, in oil-wet conditions, oil phase is located in the small pores and covers the pore surfaces, while water phase is located in the larger pores. In water-wet system, the water phase is located in the smaller pores and covers the pore surfaces, while oil phase is located in the larger pores. In an oil-wet system, the water-oil ratio increased more rapidly than in a water-wet system [58, 59].
In our previous works $[60,61]$, we concluded that the recovery factor from gel treatment in water-wet conditions was higher and the damage to the low permeability layer was less compared to oil-wet system. To assess the effects of rock wettability on the performance of CDG floods, wettability data presented in Table 15 were used, and two scenarios were compared. A linear saturation dependence was used for the high-permeability layers [25].

Table 15. Relative permeability parameters [58, 60, 61].

\begin{tabular}{llllll}
\hline Wettability & $\boldsymbol{S}_{\boldsymbol{w i}}$ & $\boldsymbol{S}_{\boldsymbol{o r}}$ & $\boldsymbol{k}_{\boldsymbol{r} \boldsymbol{w}}^{\circ}$ & $\boldsymbol{k}_{\boldsymbol{r o}}^{\circ}$ & $\boldsymbol{n}_{\boldsymbol{w}}$ \\
\hline Water-wet & 0.12 & 0.25 & 0.26 & 1 & 3 \\
Oil-wet & 0.12 & 0.28 & 0.56 & 0.8 & 1.3 \\
\hline
\end{tabular}

$$
\begin{aligned}
k_{r w} & =k_{r w}^{\circ}\left(\frac{S_{w}-S_{w i}}{1-S_{o r}-S_{w i}}\right)^{n_{w}} \\
k_{r o} & =k_{r o}^{\circ}\left(\frac{S_{o}-S_{o i}}{1-S_{o r}-S_{w i}}\right)^{n_{o}}
\end{aligned}
$$

The results of these scenarios are presented in Table 16 and Figure 12. This table shows that the incremental oil achieved by CDG flooding under the water-wet system was higher compared to the oil-wet system. In addition, for oil-wet system,
Figure 12 shows that the less permeable layer (i.e., layer 3) was damaged and that $\mathrm{CDG}$ penetrated and reduced the permeability of this layer compared to the water-wet system. This could be due to the dispersion of CDG into layer 3 in oilwet conditions, because the water phase is normally located in the larger pores under these conditions. Thus, CDG flooding was more efficient and the damage to layer 3 was less when wetting conditions of the system were water-wet.

Table 16. Recovery factor and cumulative oil under oil-wet and water-wet condition systems.

\begin{tabular}{lllll}
\hline Scheme & RF, \% & Difference of RF\% & Cum. oil, MM STB & Incremental oil, MM STB \\
\hline WF_Water-wet & 31.40 & & 3.25 & 1.26 \\
CDG_Water-wet & 43.70 & 12.30 & 4.51 & \\
WF_Oil-wet & 25.70 & & 2.66 & 1.20 \\
CDG_Oil-wet & 37.40 & 11.70 & 3.86 & 20 \\
\hline
\end{tabular}
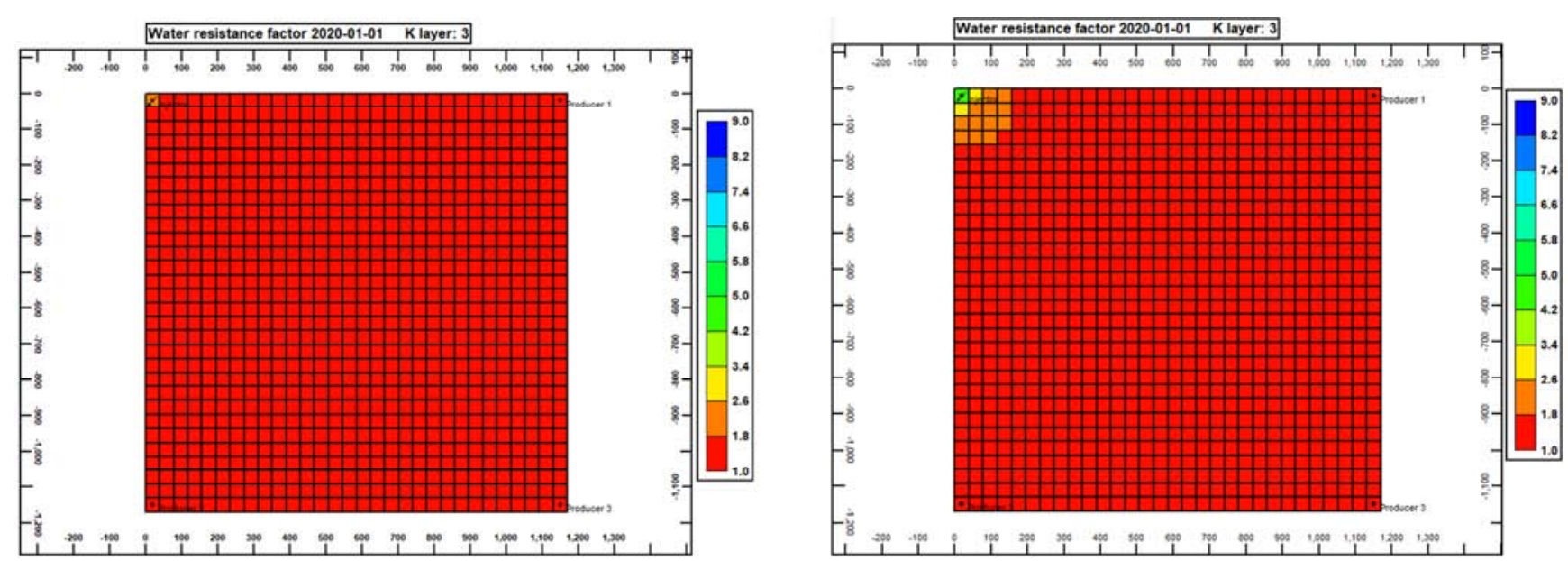

Figure 12. Comparison of residual resistance factor in layer 3 (low-permeability layer) between water-wet (left) and oil-wet conditions (right).

\subsection{Effect of Polymer/Crosslinker (P/X) Ratio}

As mentioned previously, a reaction occurs mainly because of the collisions between the molecules of the reactants. Increasing the concentrations of the reactants would result in more collisions of molecules and would thereby obtain a faster reaction and a shorter gelation time. In this section, different polymer to crosslinker ratio were utilized, where the polymer concentration was $0.05 \mathrm{wt} . \%$ [22].

Table 17 presented the results of these scenarios, which demonstrated that increasing the $\mathrm{P} / \mathrm{X}$ ratio would result in a lower recovery factor and lower incremental oil. This behavior is attributed to the fact that increasing $\mathrm{P} / \mathrm{X}$ ratio would increase the viscosity of the formed CDG; therefore, there is a shorter penetration into the high-permeability layer, as shown in Figure 13. In addition, at higher $\mathrm{P} / \mathrm{X}$ ratios, the crosslinking reaction rate would increase [6]. Thus, the higher the $\mathrm{P} / \mathrm{X}$ ratio, the lower the viscosity of the formed $\mathrm{CDG}$ and the higher the penetration into thief zones. However, the higher the $\mathrm{P} / \mathrm{X}$ ratio, the higher the residual 
resistance factor (i.e., permeability reduction).

Table 17. Recovery factor and cumulative oil under different polymer/crosslinker values.

\begin{tabular}{llllll}
\hline Polymer Conc. wt.\% & P/X ratio & RF\% & Cum. oil, MM STB & Incremental oil, MM STB & RRF \\
\hline WF & & 27.80 & 2.55 & & \\
0.05 & $10 / 1$ & 40.40 & 3.70 & 1.15 & 6.8 \\
0.05 & $20 / 1$ & 40.00 & 3.67 & 1.12 & 10.7 \\
0.05 & $30 / 1$ & 36.10 & 3.31 & 0.76 & 18.9 \\
0.05 & $40 / 1$ & 34.20 & 3.13 & 0.58 & 21.9 \\
\hline
\end{tabular}
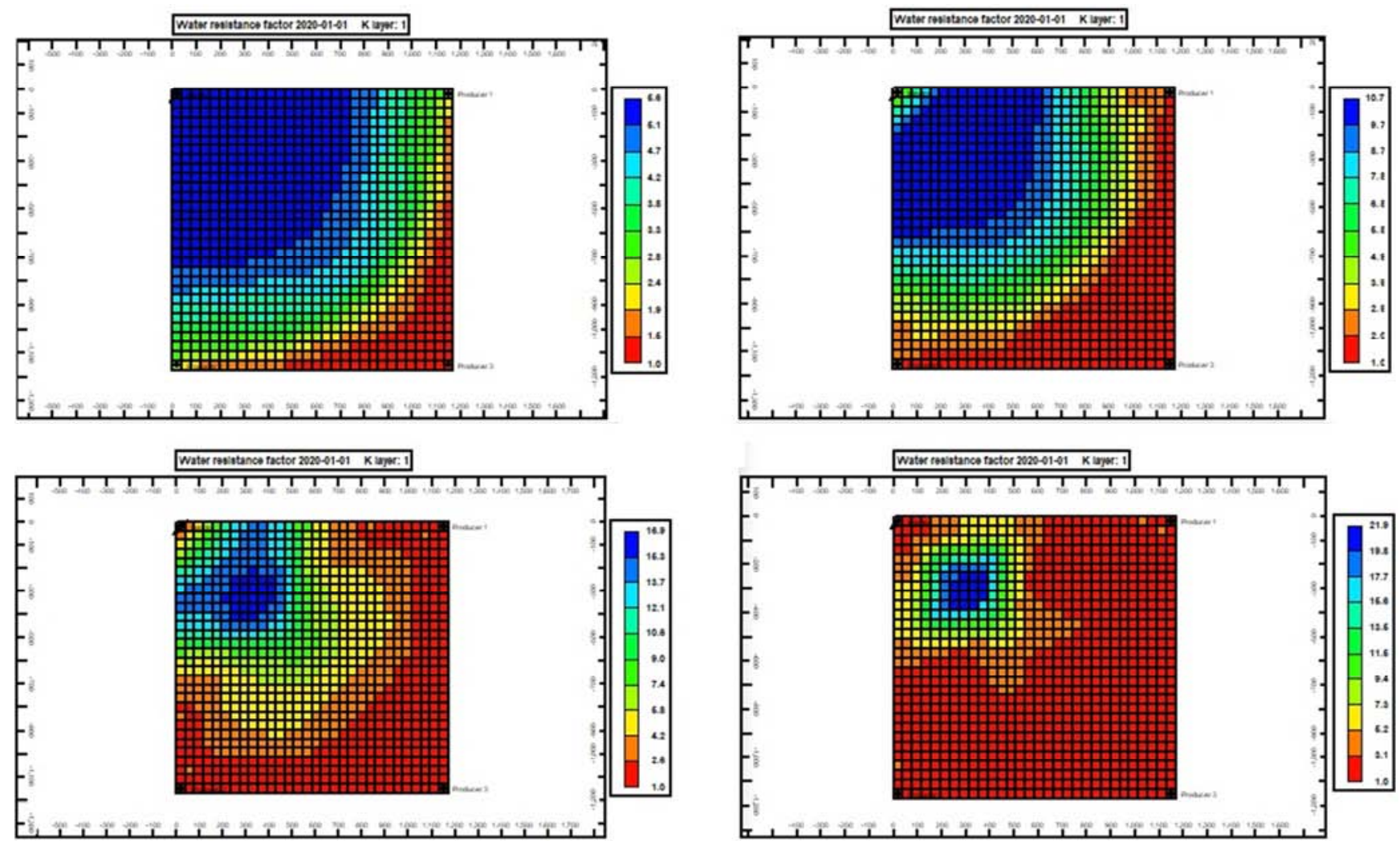

Figure 13. Comparison of residual resistance factor in layer 1 at different levels of P/X ratio (10/1 P/X (upper left), 20/1 P/X (upper right), 30/1 P/X (lower left), and 40/1 P/X (lower right)).

\subsection{Effect of Polymer Hydrolysis on the Formulation of CDG}

Since HPAM polymer solution contains nonionic amide groups $\left(\mathrm{CONH}_{2}\right)$ and anionic carboxyl groups $\left(\mathrm{COO}^{-}\right)$; thus, the hydrolysis process converts some of amide groups to carboxyl groups, which can by represented by the degree of hydrolysis. In general, HPAM polymer solution that used in field applications has a degree of hydrolysis ranges from 15$35 \%$ [1]. Converting some of amide groups to carboxyl groups will introduce negative charges on the backbones of polymer chains. In addition, increasing hydrolysis will increase the viscosity and reduce the adsorption; however, the chemical stability is reduced due to the losing of amide groups. On the other hand, low degree of hydrolysis will give high chemical stability to the polymer but the adsorption will increase due to high content of amide groups [1]. Moreover, the degree of hydrolysis could affect the retention of HPAM polymer solution in unconsolidated sandpacks [62] and the data presented by those researchers were used in this section. Thus, degree of hydrolysis plays an important role in the chemical stability of polymer, which in turn will affect the gelation process between the polymer and the crosslinker.

Table 18 and Figure 14 shows that increasing the polymer hydrolysis from $0 \%$ (unhydrolyzed) to $35 \%$ would resulted in an increase of the recovery factor and the residual resistance factor. These results proved the importance of the degree of hydrolysis on the formulation and performance of the CDG.

Table 18. Recovery factor and cumulative oil under oil-wet and water-wet condition systems.

\begin{tabular}{llllll}
\hline Polymer Conc. wt. \% & Degree of polymer hydrolysis & RF\% & Cum. oil, MM STB & Incremental oil, MM STB & RRF \\
\hline WF & & 27.80 & 2.55 & & \\
0.06 & Unhydrolyzed & 40.00 & 3.75 & 1.20 & 8.8 \\
0.06 & 15\% hydrolyzed & 41.20 & 3.77 & 1.22 & 9.0 \\
\hline
\end{tabular}




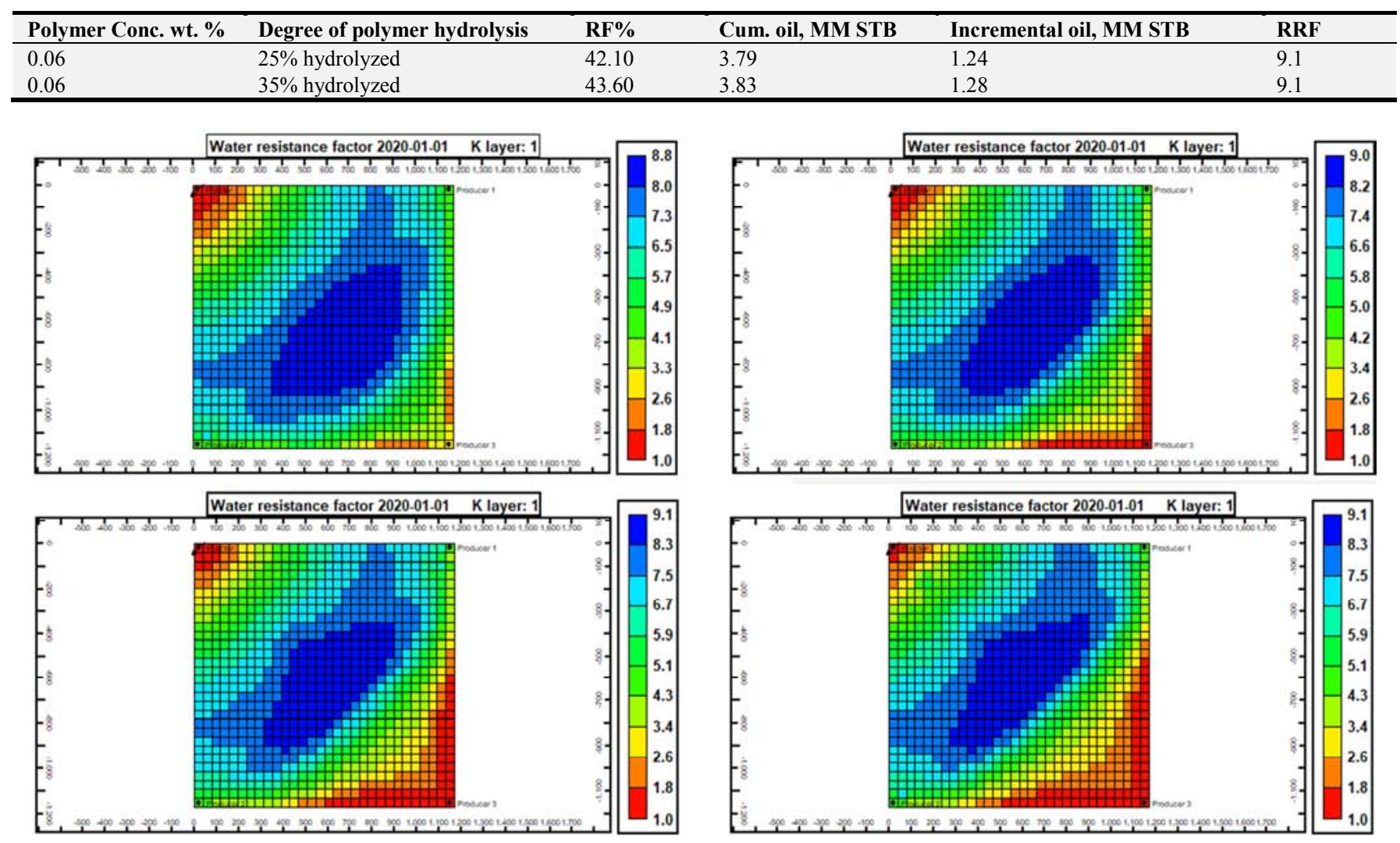

Figure 14. Comparison of permeability reduction (residual resistance factor) in layer 1 at $0 \%$ (upper left), 15\% (upper right), 25\% (lower left), and 35\% (lower right) polymer hydrolysis.

\section{Conclusions}

1. CDG propagated deeper and generated higher residual resistance factor than polymer solution in the highpermeability layers.

2. Shear-thinning behavior of CDG assisted the selective penetration into the high-permeability layers only.

3. The permeability reduction generated by CDG was not easy to remove, even with reversible adsorption and prolonged post-treatment water injection.

4. Two types of gel degradations affected the performance of CDG: chemical and mechanical degradations.

5. For both types of gel degradation, the higher the degree of degradation, the lower the recovery factor.

6. Increasing the salinity of the reservoir brine and/or the makeup water lowers the strength of the formed CDG and lower the recovery factor.

7. In-depth gel treatment should be considered the only method of blocking high-permeability layers and diverting the post-treatment water injection into the low-permeability layer for thick heterogeneous reservoir with crossflow.

8. Starting the treatment with gel followed by polymer makes the remaining crosslinkers from gel treatment attach to the subsequent injected polymer; therefore, it creates a higher recovery factor and higher incremental oil.

9. Regardless of the sequence of gel and polymer injection, the combination injection of gel and polymer always yielded higher results than using the gel treatment alone.

10. Water-wet conditions are more favorable than oil-wet conditions for the application of the CDG treatment.

11. The lower the polymer/crosslinker ratio, the higher the penetration into the high permeability layers, which leads to high recovery factor and low RRF.

12. The higher the degree of HPAM hydrolysis, the higher the recovery factor, and the higher the permeability reduction in the thief zones.

\section{Nomenclature}

$\mathrm{CDG}$
$\mathrm{C} 1, \mathrm{C} 2$, and $\mathrm{C} 3$
$K$
$\tau_{1 / 2}$
$r_{k}$
$k$

Colloidal dispersion gel

Mass concentrations in the aqueous phase

The first order rate constant

The half-life of the component (i.e., polymer and crosslinker)

Reaction rate, $\mathrm{kg} /\left(\min . \mathrm{cm}^{3}\right)$

Rate constant, $1 / \mathrm{min}$ 


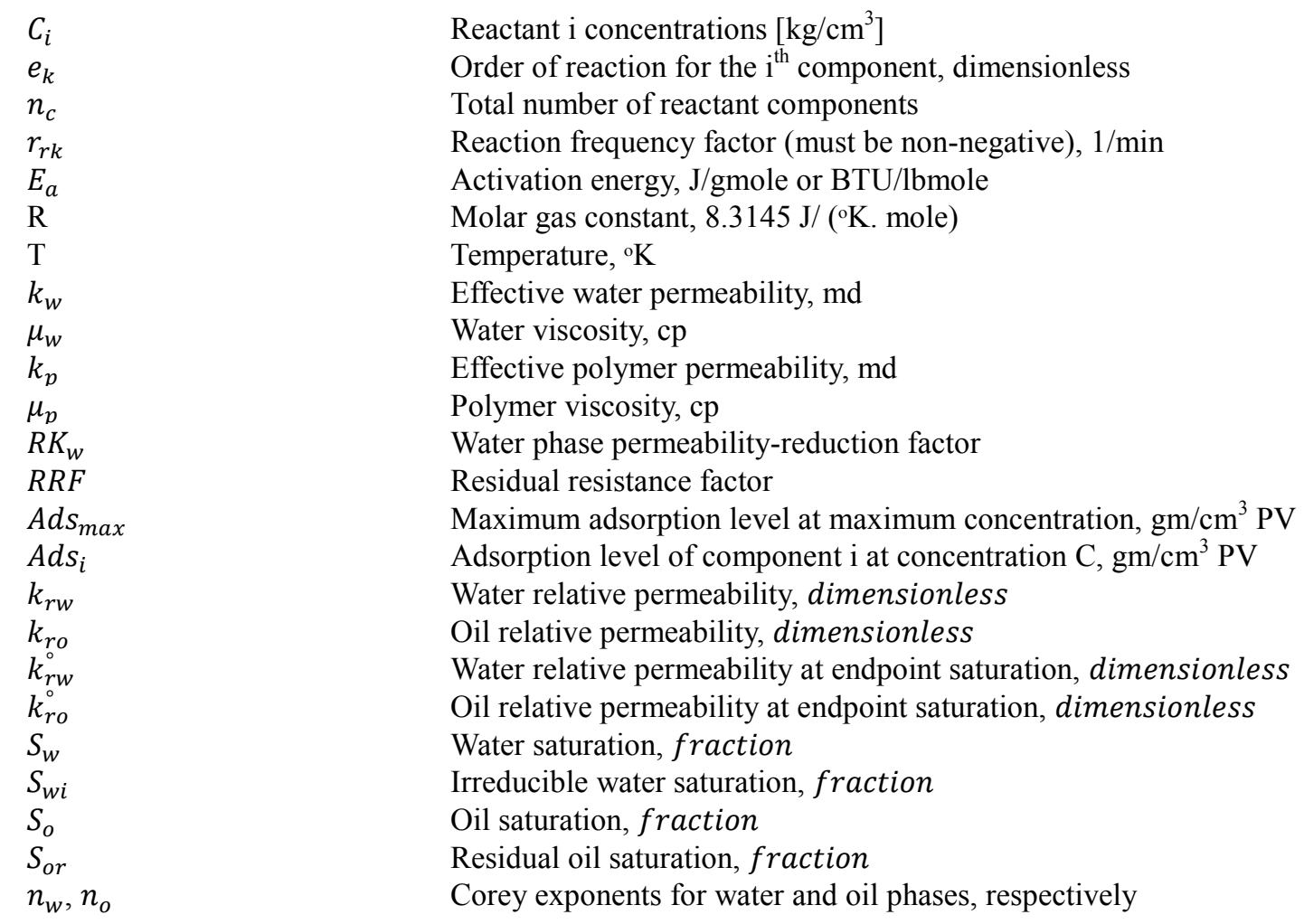

\section{Acknowledgements}

The financial support of The Iraq Ministry of Oil and ExxonMobil Iraq (through the Training Technology \& Scholars Program) is gratefully acknowledged.

\section{References}

[1] Sheng, J. J. 2011. Modern Chemical Enhanced Oil Recovery: Theory and Practice. Burlington, MA, USA: Gulf Professional Publishing.

[2] Abdulbaki, M., Huh, C., Sepehrnoori, K., et al. 2014. A Critical Review on use of Polymer Microgels for Conformance Control Purposes. J Petrol Sci \& Eng 122: 741753. https://doi.org/10.1016/j.petrol.2014.06.034.

[3] Ranganathan, R. Lewis, R., McCool, C. S. et al. 1998. Experimental Study of the Gelation Behavior of a Polyacrylamide/Aluminum Citrate Colloidal-Dispersion Gel System. SPE $J \quad 03$ (04): 337-343. SPE-52503-PA. https://doi.org/10.2118/52503-PA.

[4] Shiyi, Y., Dong, H., Qiang, W. et al. 2000. Numerical Simulation Study on Weak Gel Injection. Presented at the SPE Asia Pacific Oil and Gas Conference Exhibition, Brisbane, Australia, 16-18 October. SPE-64291-MS. https://doi.org/10.2118/64291-MS.

[5] Sydansk, R. D. 1988. A New Conformance-ImprovementTreatment Chromium (III) Gel Technology. Presented at the SPE Enhance Oil Recovery Symposium, Tulsa, Oklahoma, USA, 16-21 April. SPE-17329-MS. https://doi.org/10.2118/17329-MS.

[6] Mack, J. C. and Smith, J. E. 1994. In-Depth Colloidal dispersion Gels Improve Oil Recovery Efficiency. Paper SPE/DOE 27780 Presented at the SPE/DOE Ninth Symposium on IOR, Tulsa, Oklahoma, USA, 17-20 April. SPE-27780-MS. https://doi.org/10.2118/27780-MS.

[7] Smith, J. E., Liu, H., and Guo, Z. D. 2000. Laboratory Studies of In-Depth Colloidal Dispersion Gel Technology for Daqing Oil Field. Presented at the SPE/AAPG Western Regional Meeting, Long Beach, California, USA, 19-22 June. SPE62610-MS. https://doi.org/10.2118/62610-MS.

[8] Chang, H. L, Sui, X. Xia, L. et al. 2006. Successful Filed Pilot of In-Depth Colloidal Dispersion Gel (CDG) Technology in Daqing Oil Field. SPE Res Eval \& Eng 09 (06): 664-673. SPE-89460-PA. https://doi.org/10.2118/89460-PA.

[9] Diaz, D. Saez, N. et al. 2015. CDG in a Heterogeneous Fluvial Reservoir in Argentina: Pilot and Field Expansion Evaluation. Presented at the SPE/EOR Kuala Lumpur, Malaysia, 11-13 August. SPE-174704-MS. https://doi.org/10.2118/174704MS.

[10] Manrique, E. and Lantz, M. 2011. Colloidal Dispersion Gels (CDG) and their Application in Wyoming and Elsewhere. The $3^{\text {rd }}$ Annual Wyoming IOR/EOR Conference, Jackson Hole, Wyoming, USA.

[11] Muruaga, E., Flores, M. V., Norman, C. et al. 2008. Combining Bulk Gels and Colloidal Dispersion Gels for Improved Volumetric Sweep Efficiency in a Mature Waterflood. Presented at the SPE Symposium on Improved Oil Recovery, Tulsa, Oklahoma, USA, 20-23 April. SPE113334-MS. https://doi.org/10.2118/113334-MS.

[12] Sandoval, J. R., Manrique, E. J., Perez, H. H. et al. 2010. Dina Cretaceo Field Chemical EOR: From Screening to Pilot Design. Presented at the SPE Latin American and Caribbean Petroleum Engineering Conference, Lima, Peru, 1-3 December. SPE-139200-MS. https://doi.org/10.2118/139200MS. 
[13] Castro, R., Maya, J. et al. 2013a. Colloidal Dispersion Gels (CDG) in Dina Cretaceous Field: From Pilot Design to Field Implementation and Performance. Presented at the SPE Enhanced Oil Recovery Conference, Kuala Lumpur, Malaysia, 2-4 July. SPE-165273-MS. https://doi.org/10.2118/165273-MS.

[14] Castro, R., Maya, G. A., Sandoval, J. E. et al. 2013b. Colloidal Dispersion Gel (CDG) To Improve Volumetric Sweep Efficiency in Water Flooding Processes. CTF Cienc Tecnol Futuro 05 (03): 61-78.

[15] Fielding Jr., R. C., Gibbons, D. H., and Legrand, F. P. 1994. In-Depth Drive Fluid Diversion Using an Evaluation of Colloidal Dispersion Gels and New Bulk Gels: An Operational Case History of North Rainbow Ranch Unit. Presented at the SPE/DOE IOR Symposium, Tulsa, Oklahoma, USA, 17-20 April. SPE-27773-MS. https://doi.org/10.2118/27773-MS.

[16] Manrique, E., Reyes, S., Romero, J. et al. 2014. Colloidal Dispersion Gels (CDG): Field Projects Review. Presented at the SPE EOR Conference at Oil and Gas West Asia, Muscat, the Sultanate of Oman, 31 March-2 April. SPE-169705-MS. https://doi.org/10.2118/169705-MS.

[17] Wang, W. Gu, Y., and Liu, Y. 2003. Applications of Weak Gel for In-Depth Profile Modification and Oil Displacement. $J$ Can Pet Technol 42 (06): 54-61. PETSOC-03-06-04. https://doi.org/10.2118/03-06-04.

[18] Al-Assi, A. A., Willhite G. P., Green, D. W. et al. 2009. Formation and Propagation of Gel Aggregates using Partially Hydrolyzed Polyacrylamide and Aluminum Citrate. SPE J 14 (03): $\quad 450-461$. https://doi.org/10.2118/100049-PA. SPE-100049-PA.

[19] Seright, R. S. 1994. Propagation of an Aluminum CitrateHPAM Colloidal Dispersion Gel through Berea Sandstone. In Seright, R. 1995. Improved Techniques for Fluid Diversion in Oil Recovery Processes. Annual Report. Report No. DOE/BC/14880-10. U.S. DOE, Office of Fossil Energy, Washington, D.C., USA, September 1994 and March 1995. 51-64.

[20] Seright, R. S., Han, P., and Wang, D. 2006. Current Colloidal Dispersion Gels are not Superior to Polymer Flooding. Petrol Geol \& Oilfield Develop in Daqing 25 (05): 71-80. Article ID: 1000-3754 (2006) 05-0071-10.

[21] Diaz, D., Somaruga, C., Norman, C. et al. 2008. Colloidal Dispersion Gels Improve Recovery in a Heterogeneous Argentina Waterflood. Presented at the SPE Symposium on IOR, Tulsa, Oklahoma, USA, 20-23 April. SPE-113320-MS. https://doi.org/10.2118/113320-MS.

[22] Alvand, E., Aalaie, J., Hemmati, M. et al. 2016. Colloidal dispersion gels based on sulfonated polyacrylamide and chromium triacetate for harsh-environment. Korean $\mathrm{J}$ Chem Eng 33 (06): 1654-1963. http://doi.org/10.1007/s11814-0160025-6.

[23] Helleren, J. 2011. Numerical Simulation of Chemical FlowZone Isolation. M.Sc. Thesis, University of Stavanger, Faculty of Science and Technology, Department of Petroleum Engineering. http://hdl.handle.net/11250/183325.

[24] Al-Muntasheri, G. A., Nasr-El-Din, H. A., and Zitha, P. L. J. 2008. Gelation kinetics of an Organically Cross-Linked Gel at High Temperature and Pressure. SPE J 13 (03): 337-345. SPE104071-PA. http://dx.doi.org/10.2118/104071-PA.
[25] Scott, T., Roberts, L. J., Sharpe, S. R., et al. 1987. In-situ Gel Calculations in Complex Reservoir Systems using a New Chemical Flood Simulator. SPE Res Eng 02 (04): 634-646. SPE-14234-PA. https://doi.org/10.2118/14234-PA.

[26] CMG-STARS User Guide, 2015.

[27] Clifford, P. J. and Sorbie, K. S. 1985. The Effects of Chemical Degradation on Polymer Flooding. Presented at the International Symposium on Oilfield and Geothermal Chemistry, Phoenix, Arizona, USA, 9-11 April. https://doi.org/10.2118/13586-MS.

[28] Chauveteau, G., and Kohler, N. 1974 Polymer Flooding: The Essential Elements for Laboratory Evaluation. Presented at SPE/IOR Symposium, 22-24 April. Tulsa, Oklahoma, SPE4745-MS. https://doi.org/10.2118/4745-MS.

[29] Seright, R. S. and Martin, F. D. 1993. Impact of Gelation pH, Rock Permeability, and Lithology on the Performance of a Monomer-Based Gel. SPE Res Eng 08 (01): 43-50. SPE20999-PA. https://dx.doi.org/10.2118/20999-PA.

[30] Jennings, R. R., Rogers, J. H., and West, T. J. 1970. Factors Influencing Mobility Control by Polymer Solutions. JPT 23, (03): 391-401, SPE-2867-PA. https://doi.org/10.2118/2867-PA.

[31] Needham, R. B. and Doe, P. H. 1987. Polymer Flooding Review. J Pet Technol 39 (12): 1503-1507. SPE-17140-PA. https://doi.org/10.2118/17140-PA.

[32] Bai, B., Wang, Q., Du, Y. et al. 2004. Factors Affecting InDepth Gel Treatment for Reservoirs with Thick Heterogeneous Oil Layers. Presented at the fifth Canadian International Petroleum Conference, Calgary, Alberta, Canada, 8-10 June. PETSOC-2004-140. https://doi.org/10.2118/2004-140.

[33] Carpenter, C. 2016. Colloidal-Dispersion Gel in a Heterogeneous Reservoir in Argentina. J Pet Technol 68 (06): 82-83. SPE-0616-0082-JPT. https://doi.org/10.2118/06160082-JPT.

[34] Seright, R. S, Zhang, G., Akanni, O. et al. 2012. A Comparison of Polymer Flooding with In-Depth Profile Modification. J Can Pet Technol 51 (5): 393- 402. SPE146087-PA. https://doi.org/10.2118/146087-PA.

[35] Zhidong, G., Chang, H. L., Fan, C. et al. 2011. Comparison of Oil Displacement Characteristics between CDG and Polymer Flooding in the Daqing Oilfield. Presented at the SPE Enhanced Oil Recovery Conference, Kuala Lumpur, Malaysia, 19-21 July. SPE-144119-MS. https://doi.org/10.2118/144119-MS.

[36] Seright, R. S. 1988. Placement of Gels to Modify Injection Profiles. Presented at the SPE Enhanced Oil Recovery Symposium, Tulsa, Oklahoma, USA, 16-21 April. SPE17332-MS. https://doi.org/10.2118/17332-MS.

[37] Seright, R. S. 1991. Effect of Rheology on Gel Placement. SPE Res Eng 06 (02): 212-218. SPE-18502-PA. https://doi.org/10.2118/18502-PA.

[38] Seright, R. S. 1996. Improved Methods for Water Shutoff. PRRC Report 96-23, Semi-Annual Technical Report, Submitted to BDM-OKLAHOMA/The US DOE.

[39] Hoefner, M. L., Seetharam, R. V., Shu, P. et al. 1992. Selective Penetration of Bioploymer profile-Control Gels: Experiment and Model. $J$ of Petrol Sci \& Eng 07 (1-2): 53-66. https://doi.org/10.1016/0920-4105(92)90008-O. 
[40] Lee, K. S. 2011. Performance of a Polymer Flood with ShearThinning Fluid in Heterogeneous Layered Systems with Crossflow. Energies $04 \quad$ (08): 1112-1128. https://doi.org/10.3390/en4081112.

[41] Green, D. W. and Willhite, G. P. 1998. Enhanced Oil Recovery, Society of Petroleum Engineers, Richardson, Texas, USA.

[42] Wang, D., Seright, R., Zhenbo, S. et al. 2007. Key Aspects of Project Design for Polymer Flooding. Presented at the SPE Annual Technical Conference and Exhibition, Anaheim, California, USA, 11-14 November. SPE-109682-MS. https://doi.org/10.2118/109682-MS.

[43] Manichand, R. N. and Seright, R. 2014. Field vs. Laboratory Polymer-Retention Values for a Polymer Flood in the Tambaredjo Field. SPE Res Eval \& Eng 17 (03): 314-325. SPE-169027-PA. https://doi.org/10.2118/169027-PA.

[44] Hoteit, H., Alexis, D., Adepoju, O. O. et al. 2016. Numerical and Experimental Investigation pf polymer-Induced Resistance to Flow in Reservoirs Undergoing a Chemical Flood. Presented at the SPE Annual technical Conference and Exhibition, Dubai, UAE, 26-28 September. SPE-181720-MS. https://doi.org/10.2118/181720-MS.

[45] Asen, S. M., Stavland, A., Strand, D. et al. 2018. An Experimental Investigation of Polymer Mechanical Degradation at $\mathrm{cm}$ and $\mathrm{m}$ Scale. Presented at the SPE Improved Oil Recovery Conference, Tulsa, Oklahoma, USA, 14-18 April. SPE-190225-MS. https://doi.org/10.2118/190225-MS.

[46] Morris, C. W. and Jackson, K. M. 1978. Mechanical Degradation of Polyacrylamide Solutions in Porous Media. Presented at the SPE Symposium on Improved Oil Recovery, Tulsa, Oklahoma, USA, 16-17 April. SPE-7064-MS. https://doi.org/10.2118/7064-MS.

[47] Sorbie, K. S. 1991. Polymer-Improved Oil Recovery, CRC Press, Boca Raton, Florida, USA (1991).

[48] Sorbie, K. S. and Roberts, L. J. 1984. A Model for Calculating Polymer Injectivity Including the Effects of Shear Degradation. Presented at the SPE Enhance Oil Recovery Symposium, Tulsa, Oklahoma, USA, 15-18 April. SPE12654-MS. https://doi.org/10.2118/12654-MS.

[49] Zaitoun, A., Makakou, P., Blin, N. et al. 2012. Shear Stability of EOR Polymers. SPE J 17 (02): 335-339. SPE-141113-PA. https://doi.org/10.2118/141113-PA.

[50] Brakstad, K. and Rosenkilde, C. 2016. Modelling Viscosity and Mechanical Degradation of Polyacrylamide Solutions in Porous Media. Presented at the SPE Improved Oil Recovery Conference, Tulsa, Oklahoma, USA, 11-13 April. SPE179593-MS. https://doi.org/10.2118/179593-MS.

[51] Sheng, J. J. 2015. Status of surfactant EOR technology. J. Petrol 01 (02): 97-105. https://doi.org/10.1016/j.petlm.2015.07.003.
[52] Aldhaheri, M. N., Wei, M., and Bai, B. 2016. Comprehensive Guidelines for the Application of In-Situ Polymer Gels for Injection Well Conformance Improvement Based on Field Projects. Presented at the SPE Improved Oil Recovery Conference, Tulsa, Oklahoma, USA, 11-13 April. SPE179575-MS. https://doi.org/10.2118/179575-MS.

[53] Abdulbaki, M. R. 2012. Simulation Study of Polymer Microgel Conformance Treatments. Master Thesis. The University of Texas at Austin, Austin, Texas, USA (2012).

[54] Aluhwal, O. 2008. Simulation Study of Improving Oil Recovery by Polymer Flooding in a Malaysian Reservoir. Master Thesis, Universiti Teknologi Malaysia. Kuala Lumpur, Malaysia (2008).

[55] Sedaghat, M. H., Ghazanfari, M. H., Masihi, M. et al. 2013. Experimental and numerical investigation of polymer flooding in fractured heavy oil five-spot systems. J Petrol Sci Eng 108: 370-382. https://doi.org/10.1016/j.petrol.2013.07.001.

[56] Vossoughi, S. 2000. Profile modification using in-situ gelation technology- A review. J Petrol Sci \& Eng 26 (1-4): 199-209. https://doi.org/10.1016/S0920-4105(00)00034-6.

[57] Ahmed, T. 2001. Reservoir Engineering Handbook $2^{\text {nd }}$ Edition, Gulf Professional Publishing.

[58] Shen, G. X., Lee J. H., and Lee, K. S. 2013. The Effects of Wettability on Gel Performance in Layered Heterogeneous Reservoirs. Applied Mechanics and Materials 448-453: 40284032. http://doi.org/10.4028/www.scientific.net/AMM.448453.4028

[59] Shen, G. X., Lee J. H., and Lee, K. S. 2014. Influence of Temperature on Gel Treatment under Various Reservoir Wettability Conditions. Presented at the Offshore Technology Conference Asia. Kuala Lumpur, Malaysia, 25-28 March. OTC-24853-MS. https://doi.org/10.4043/24853-MS.

[60] Tariq K. Khamees and Ralph E. Flori 2018. A comprehensive evaluation of the parameters that affect the performance of insitu gelation system. Fuel 225: 140-160. https://doi.org/10.1016/j.fuel.2018.03.115.

[61] Tariq K. Khamees, Ralph E. Flori, Ahmed A. Alsubaih et al. 2018. Modeling the Effects of Salinity, Polymer Rheology, Temperature, and Reservoir Wettability on the Performance of In-Depth Gel Treatment Coupled with Surfactant and Polymer Flooding. Presented at the Abu Dhabi Petroleum Exhibition \& Conference, Abu Dhabi, UAE, 12-15 November. SPE-193011MS. https://doi.org/10.2118/193011-MS.

[62] Martin, F. D. and Shrewood, N. S. 1975. The Effect of Hydrolysis of Polyacrylamide on Solution Viscosity, Polymer Retention and Flow Resistance Properties. Presented at the SPE Rocky Mountain Regional Meeting, Denver, Colorado, USA. 7-9 April. SPE-5339-MS. https://doi.org/10.2118/5339MS. 